Technical Report Documentation Page

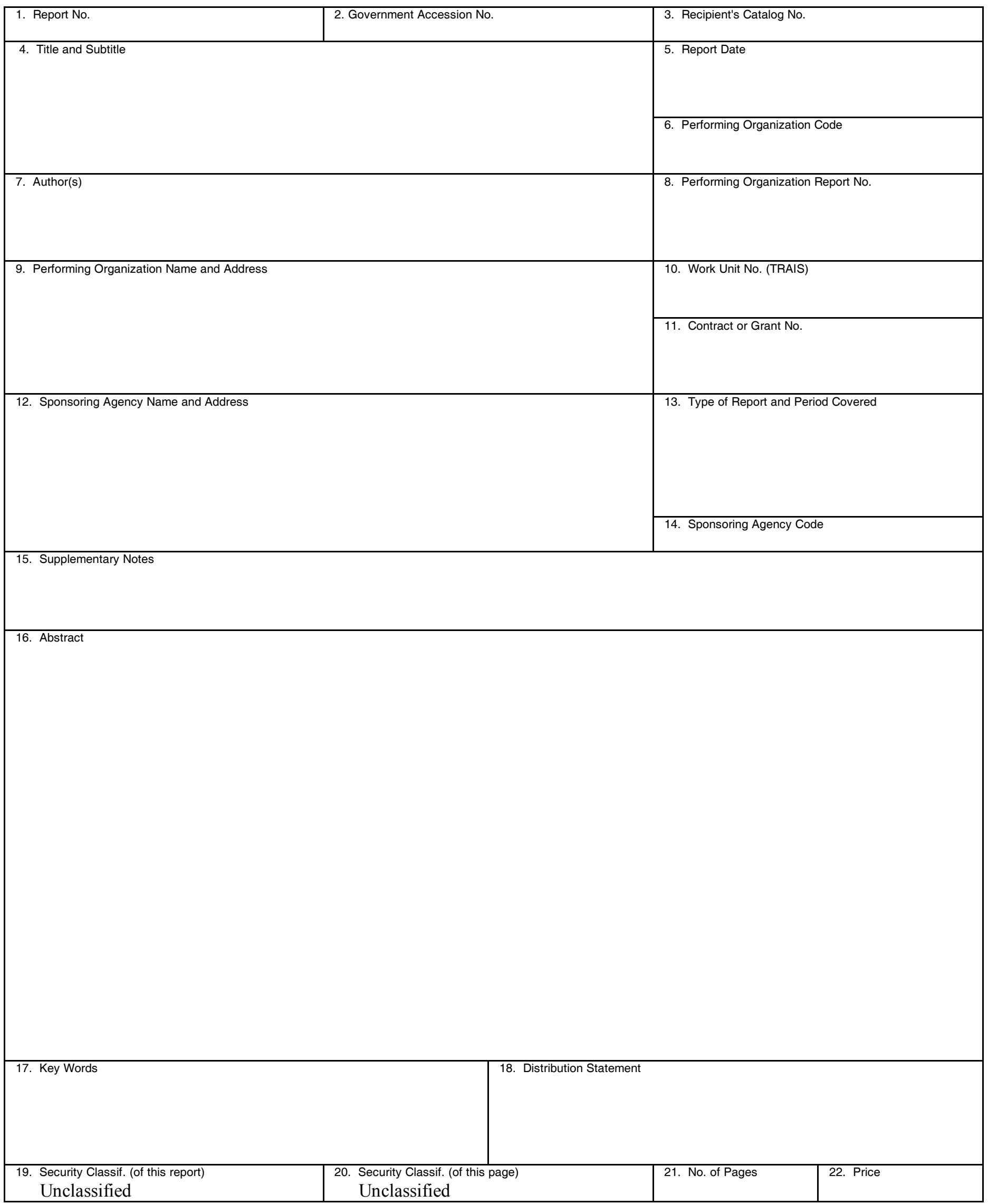

Form DOT F 1700.7 (8-72)

Reproduction of completed page authorized 


\title{
Simultaneous Imaging of Fuel, OH, and Three Component Velocity Fields in High Pressure, Liquid Fueled, Swirl Stabilized Flames at $5 \mathbf{k H z}^{1}$
}

\author{
Ianko Chterev $^{\mathrm{a}}$, Nicholas Rock ${ }^{\mathrm{a}}$, Hanna Ek $^{\mathrm{a}}$, Benjamin Emerson $^{\mathrm{a}}$, Jerry Seitzman $^{\mathrm{a}}$, Naibo Jiang $^{\mathrm{b}}$, Sukesh Roy $^{\mathrm{b}}$, \\ Tonghun Lee ${ }^{\mathrm{c}}$, James Gord ${ }^{\mathrm{d}}$, and Tim Lieuwen ${ }^{\mathrm{a}}$ \\ ${ }^{a}$ Georgia Institute of Technology, Atlanta, GA 30332 \\ ${ }^{\mathrm{b}}$ Spectral Energies, LLC, OH 45431 \\ ${ }^{\mathrm{c}}$ University of Illinois, Urbana, IL 61801 \\ ${ }^{\mathrm{d}}$ Air Force Research Laboratory, Wright-Patterson AFB, OH 45433
}

\begin{abstract}
This paper describes implementation of simultaneous, high speed $(5 \mathrm{kHz})$ stereo PIV, OH and fuel-PLIF in a pressurized, liquid fueled, swirl stabilized flame. The experiments were performed to characterize the flowfield, qualitative heat release and fuel spray distributions, and flame dynamics. Acquiring high speed OH-PLIF in pressurized, liquid fuel systems is difficult due to the strong overlap of the fuel's absorption and emission spectra with the $\mathrm{OH}$ fluorescence spectrum. To overcome difficulties associated with the overlap, the $\mathrm{OH}$ and fuel fluorescence signals were partially separated by using two cameras with differing spectral filters and data acquisition timing. Upon data reduction, regions containing fuel, $\mathrm{OH}$ and a mixture of fuel and $\mathrm{OH}$ are identified. Instantaneous and time-averaged results are discussed showing the flow field, flame position and dynamics, and spray distribution from the fuel signal for two multi-component liquid fuels, at two inlet temperatures and three pressures. These results are used to infer several important observations on coupled flow and flame physics. Specifically, the flame is "M-shaped" at higher preheat temperature and higher fuel/ air ratio, as opposed to no visible reaction on the inside of the annular fuel/air jet at low temperature and fuel/air ratio conditions. While such fundamentally different flame topologies in gaseous, premixed flames are well known, these results show that there are also different families of flame shapes and heat release distributions in spray flames. In addition, the flame position with respect to the flow is different for the liquid-fueled flame than for gaseous, premixed flames - in premixed flames with this geometry, the flame lies in the low velocity shear layer separating the reactants and the recirculating products. In contrast, the flame location is controlled by the spray location in this spray flame, as opposed to the shear layer. For example, reactions are observed near the nozzle outlet in the core of the high velocity annular jet, something which would not be observed in the premixed flame configuration. Also of interest is the near invariance of the key flow features such as jet core trajectory or shear layer locations - to the operating condition changes for this study, even as the spray penetration and distribution, and flame position change appreciably.
\end{abstract}

\section{Introduction}

Decreasing the harmful emissions from gas turbine combustors, without compromising their operational limits, requires improved understanding of internal reacting flow processes. Emissions and operational limits are influenced by (1) gas phase velocity field, (2) liquid phase fuel distribution, including droplet velocity, sizes, and morphology, (3) heat release, (4) gas phase fuel distribution and local fuel/air ratio, and (5) key scalar species distributions. These quantities can be directly tied to emissions characteristics, such as particulates, unburned hydrocarbons, and NOx, as well as operability characteristics, such as combustion instability, ignition, and blowoff. For example, gas phase fuel/air ratio distributions play important role in ignition probabilities and blowoff boundaries, while the axial heat release distribution (which is more fundamentally controlled by liquid fuel distribution, flow velocity, etc.) is an important factor in combustion instability limits.

Before discussing flow/flame physics in these combustors, we first consider basic issues and progress in the various diagnostics which can be employed. With innovations in laser systems, intensifiers, and cameras in recent years, high speed imaging for combustion research has seen a rapid increase using either short bursts of pulses [1,2] or sustained high repetition pulse trains [3-5]. High speed $(\mathrm{kHz})$, spatially resolved imaging techniques provide

${ }^{1}$ This paper is based on AIAA paper \# 2017-0152, presented at SciTech 2017 
important insights into these dynamic processes. High speed particle image velocimetry (PIV) systems have enabled significant improvements in understanding the morphology of unsteady, premixed, three dimensional swirling flows $[3,6]$, while high speed planar laser-induced fluorescence (PLIF) techniques, particularly systems imaging $\mathrm{OH}$ radical distribution, have enabled simultaneous visualizations of the flame zone with $\mathrm{kHz}$ rate temporal resolution, in order to study the flow and flame physics [4, 5, 7-12]. Significant challenges arise, however, when making measurements in multi-phase (liquid fueled), high pressure, reacting environments. First, the cost and complexity associated with operating high pressure, high power rigs pose challenges in optimizing the setup over multiple iterations. Also, the need to image through multiple optical windows introduces additional issues, such as scattering, window fouling from soot or PIV seed particles, and optical distortions. Viewing windows, which must be able to withstand the pressurized and high temperature conditions, must also have high transmittance when performing diagnostics in the UV range. In addition, the vibrations and noise of the combustor may require the laser system to be physically separated from the test cell, requiring a longer beam path that is more vulnerable to vibrations. Finally, it is difficult to differentiate regions containing fuel from those containing $\mathrm{OH}$ when doing fluorescence measurements with complex fuels.

Many prior workers have reported results from high pressure, liquid-fueled, reacting PIV. Examples of such low repetition rate work are from Hochgreb's group [13, 14] and researchers at DLR [15, 16], and high repetition rate examples come from Slabaugh et al. [17, 18]. OH-PLIF has been performed at low repetition rates in reacting flow systems with liquid fuel. Allen et al. [19] described OH-PLIF measurements on neat fuel sprays (heptane, methanol and ethanol) from 1 to 10 bar, and observed interference from polycyclic aromatic hydrocarbons (PAH) fluorescence. The PAH levels increased with pressure, similar to soot production, as also noted in other studies [20, 21]. Frank et al. [22] presented $10 \mathrm{~Hz} \mathrm{OH}$ fields at varying global fuel/air ratios and pressures up to 20 bar with liquid fuel. Locke et al. performed $10 \mathrm{~Hz}$ OH-PLIF in a swirl-stabilized fuel tube combustor with JP-8 spray at

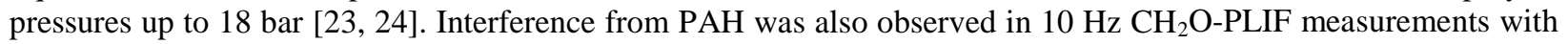
n-dodecane at 60 bar from Skeen et al. [25].

Initial work on high-speed OH-PLIF imaging in a liquid-fueled, swirl combustor employed multiple, low repetition-rate lasers to create an eight shot burst at pressures up to 13 bar [26]. Similarly, in IC engines OH-PLIF has been obtained with short bursts of pulses [27] and sustained high repetition rate imaging [28, 29]. Recently, continuous (non-burst mode) high speed, simultaneous PIV and OH-PLIF has been applied to liquid-fueled combustors [17, 18] and IC engines [29].

The current work focuses on simultaneous high speed stereoscopic PIV (sPIV), OH- and fuel-PLIF measurements in high pressure, liquid-fueled, swirling, reacting flows. The main challenges identified by the above studies and others with obtaining these measurements are outlined as follow. First, PIV suffers from interference caused by liquid droplet scattering, as the droplets may be brighter than the seeding particles. This produces a measured velocity bias as large droplets may not follow the flow well. Two options are to mask out the region of spray from the PIV fields $[15,16]$ or attempt to separate the spray and seeding particles before PIV processing [17, 18]. In the present work we employ a new approach along the lines of the latter, by using simultaneous PLIF data to identify gaseous and liquid spray regions in the PIV images, thus, enabling calculation of conditioned gaseous velocity fields and liquid velocity fields.

Next consider LIF measurements. Some key challenges associated with OH-LIF in high pressure, liquid fuel combustion are [30-33]: (1) reduction of fluorescence yield due to increase in collisional quenching (mitigated somewhat by increase in number density); (2) collisional broadening (decay in strength of spectral lines) and overlap of the excitation lines, (3) fluorescence trapping due to the increased optical density at high pressure, (4) laser energy absorption by liquid fuel and higher gas concentration, and (5) interference from liquid fuel and unburnt hydrocarbon fluorescence resulting from fuel decomposition.

High speed measurements add further complications, as the excitation energy (per pulse) is reduced substantially. A typical high speed dye laser system has pulse energies in the $\sim 100 \mu \mathrm{J}$ range, compared to $\sim 10 \mathrm{~mJ}$ for low speed Nd:YAG-pumped dye lasers and optical parametric oscillators (OPOs), and $\sim 100 \mathrm{~mJ}$ for tunable excimer lasers [19]. We note that pulse-burst laser systems are becoming increasingly useful for high energy, high to ultrafast $(\mathrm{MHz})$ repetition applications, albeit suffering from a low number of laser pulses (low hundreds). For PLIF applications pulse-burst lasers can be used to pump OPOs at $\sim 10-50 \mathrm{kHz}$ rates for pulse energies up to $~ 100 \mathrm{~mJ}$ [3436]. The high pulse energy of the lower repetition rate and pulse-burst systems produces better contrast in the fluorescence signal, compensating for the losses associated with fluorescence quenching (challenge 1 above), trapping (2), and laser energy depletion. In practice, the interference from fuel and other hydrocarbons (4) are the most critical issue, as shown in the earlier high speed imaging work in similar flames [26] and require specialized detection and post-processing schemes discussed in this work. 
Despite these difficulties, the simultaneous deployment of such flow and scalar measurements clearly enables significant insights into the structure of the coupled flow, spray, flame, and other scalars such as pollutants, which would not be possible if the measurements were made in isolation. Furthermore, these insights can materially differ when the measurements are in aero engine relevant conditions vs. conditions more conducive to optical diagnostics (such as low pressure conditions). For example, such measurements are now routinely used in the engine community to provide insight into flame-flow-spray interactions. For example, Peterson and Sick [29] utilized simultaneous PLIF, PIV, and spark energy measurements in an optical engine to show that spark energy observed linearly increased with shear strain rate. Skeen et al. [25] presented simultaneous formaldehyde PLIF (requiring techniques to separate the fluorescence from polycyclic aromatic hydrocarbons, PAH, from the formaldehyde, as discussed above) and Mie scattering to show that low temperature reactions initiate on the radial edges of the spray and forms rapidly near the injector after the end of injection. Müller et al. [28] presented OH-PLIF measurements in an optical engine with variable valve timing, showing the pronounced slowing of flame kernel growth after ignition as exhaust gas recirculation levels increased.

Similarly, simultaneous PLIF and PIV measurements are now standard measurement approaches for understanding thermoacoustic instabilities in swirl burners. These measurements clearly demonstrate that the structure of these flows are strongly three-dimensional, being dominated by large scale helical flow structures and precession of flow/flame features. As such, application of, for example, line of sight chemiluminescence measurements alone is of limited value in understanding flame-flow interactions. For example, Steinberg et al. [5] presented simultaneous PIV, OH-PLIF, and $\mathrm{OH}^{*}$ chemiluminescence in a thermoacoustically unstable swirl burner and were able to show how the interactions between a helical flow disturbance led to flame area distortions and heat release oscillations that led to the instability. They also showed how the regions of acoustic amplification and damping varied in space and time. Arndt et al. [4] presented results using the same diagnostics and showed clearly how the transition to instability was associated with a change in flame stabilization location; specifically, a liftoff of the flame from the burner nozzle.

Similar conclusions apply in spray combustors. For example, in a series of papers [13, 14, 37] Hochgreb's group used simultaneous phase Doppler particle analyzer (PDPA), PIV, and chemiluminescence measurements in a gas turbine combustor to compare a biodiesel and Jet-A liquid fuel and showed, for instance, that changing the fuel composition had relatively little impact on the flow field (a similar observation as in this study), but could correlate changes in flame length with the different droplet evaporation characteristics. Lantz et al. [26] employed PLIF at multiple wavelengths (to visualize liquid and gas phases of the fuel, as well as $\mathrm{OH}$ ) and Mie scattering in a high pressure gas turbine burner and showed how the $\mathrm{OH}$-containing regions appeared both inside and outside of the fuel spray cone, consistent with the observations in this study at some conditions. Such inferences are highly significant for understanding the space-time structure of the heat release, as it influences thermal loadings on combustor hardware as well as thermoacoustic instabilities. Slabaugh et al. [17] presented $5 \mathrm{kHz}$ simultaneous PIV and OH-PLIF to enable similar observations - for example, they quantified the spatial structure of the flame surface density with respect to key geometric details of the burner, such as the pilot or annular bluff body features, and flow field, such as regions of high shear. Specifically, they showed regions of high flame surface density in regions of high turbulence intensity where partially premixed and pre-vaporized reactants meet recirculating hot combustion products. Locke et al. [23] presented OH-PLIF measurements in a lean direct injection combustor at 10 atm and showed how LDI injector design influence flame location, for example, showing how one injector design led to poor mixing and localized hot spots along the combustor wall. Meier et al. [16] presented PIV, OH PLIF, chemiluminescence, and LII measurements in in a high pressure, three nozzle combustor sector to analyze the coupled interactions of the flow, flame, and soot production. One observation particularly worth highlighting with respect to the results of the present study is the location of the flame with respect to the high velocity air jet. Their chemiluminescence measurements suggest that the reaction zone exists in a region of high axial velocities, an interpretation they deemed questionable. Our measurements are consistent with this observation and, as discussed later, demonstrate the fundamental difference between reaction zone location in a premixed flame and a spray flame.

A significant portion of the present work focuses on data reduction to separate the $\mathrm{OH}$ and fuel signals, and analysis of the resulting images. Once the time-resolved detailed measurements are obtained, the next challenge is to reduce the resulting large amounts of instantaneous data into a form which can be used to study flame/flow physics and interactions, sensitivities to operating conditions, and compare with and validate CFD. A few examples from the above-reviewed studies and the broader literature for developing reduced basis descriptions of data sets include proper orthogonal decomposition (POD) analysis for flame-flow dynamic interactions $[5,38]$ and dynamic mode decomposition (DMD) for deconvolution of dynamic flow structures [39, 40].

The substantive progress that has been made in obtaining scalar and flow measurements in pressurized, liquid fueled systems enables significant new insights to be obtained into confined reacting flow physics. The key 
contribution of this paper is to provide insights into the combustion physics of high pressure liquid fueled aero engine type combustors by applying simultaneous sPIV, OH-PLIF, and fuel-PLIF. Results are presented at operating pressures of 2-5 bar, with two different liquid fuels to show the simultaneous structures of the spray, flame position, and gas and liquid phase flow field. Observations are presented on the effects of operating conditions and fuel type on spray distribution, flame shape, and flame anchoring characteristics.

\section{Experimental Facility and Diagnostics}

\subsection{Combustor Design}

The facility details are reproduced below. Key components include air supply and preconditioning, fuel supply, the optically accessible pressure vessel and liner, fuel injector, and exhaust section. Compressed air at pressures up to $20 \mathrm{bar}$ is heated to preheat temperatures, $T_{\mathrm{ph}}$, from 350 to $750 \mathrm{~K}$. Following this heating process, a portion of the air is sent to the test section and the remainder is cooled to approximately $320 \mathrm{~K}$ in a heat exchanger. This secondary air flows around the liner and keeps the pressure vessel structure and windows cool. Hot combustion products mix with the cooling air downstream of the test section and exit through a water cooled exhaust. A choked orifice plug of variable size is installed at the exhaust exit to maintain a prescribed pressure in the combustion chamber. Air mass flow rates are calculated using a vortex flowmeter (Rosemount, model 8800). The air temperature is measured with a K-type thermocouple $350 \mathrm{~mm}$ upstream of the dump plane, and its value was continuously recorded during measurements. Its value typically remained within $\pm 10 \mathrm{~K}$ of the nominal value during a measurement. The uncertainty in the nozzle velocity calculation is estimated to be $\sim 2 \%$, calculated by standard uncertainty propagation approaches.

The combustor liner consists of a $305 \mathrm{~mm}$ long, $105 \mathrm{~mm}$ inside diameter quartz tube. The front end of the liner, or nozzle outlet, referred to as the "bulkhead" in this paper consists of a stainless steel wall without secondary cooling passages, and is shown in Figure 2. This bulkhead face contains four thermocouples situated flush with the surface for monitoring bulkhead temperature, a static pressure transducer, and an ignitor. Uncertainties in combustor pressure measurements are estimated to be $\sim 1.0 \%$.

The pressure vessel that the liner is mounted in has optical access on all four sides, through four quartz windows with dimensions $205 \times 110 \times 50 \mathrm{~mm}$, as shown in Figure 1. Prior to entering the test section, the pressurized, preheated air passes through the swirler depicted in Figure 1 (right), with a nozzle diameter, $D_{0}$, following a design from Cohen and Rosfjord [41]. As shown in Figure 1 (right), air travels through two separate swirler passages. The air exits the nozzle with an average bulk velocity of $65-85 \mathrm{~m} / \mathrm{s}$, depending on operating conditions (see Table 1). The airblast filming nozzle consists of $6 \times 0.18 \mathrm{~mm}$ diameter holes that spray radially into the flow.

The fuel of interest was pressurized using nitrogen, and the fuel flow was regulated by adjusting the fuel line pressure using a pressure regulator. Fuel flow rates were measured using an AW-Lake positive displacement gear meter. The estimated uncertainty in overall fuel/air equivalence ratio $(\phi)$ is $\sim 3 \%$. In between test conditions, when no liquid fuel was flowing but the combustor was hot, the fuel injector orifices were purged using nitrogen flow to prevent fuel coking. Fuel temperatures were measured at the fuel inlet depicted in Figure 1 and varied between 300 and $305 \mathrm{~K}$.

The data presented here are at various conditions and with two fuels indicated in Table 1 . The C-5 fuel is a high aromatics content fuel (decane + trimethylbenzene), with a low boiling point and low viscosity compared to Jet-A [42], chosen as a fuel with contrasting atomization properties.

\subsection{High Speed Stereo PIV Setup}

The PIV light source is a dual head, frequency doubled, diode pumped, solid state, Nd:YLF $527 \mathrm{~nm}$ laser, with 2 $\mathrm{mJ}$ pulse energy, pulse duration of about $200 \mathrm{~ns}$, and dual pulse separation of $16 \mu \mathrm{s}$. A $2.0 \mathrm{~mm}$ thick and $3.70 D_{0}$ wide laser sheet was formed using a combination of cylindrical lenses. It entered through the top of the combustor and was aligned in the $r-z$ direction to within $0.5 \mathrm{~mm}$ to the combustor centerline as shown in Figure 3. Data are acquired at $5 \mathrm{kHz}, 7500$ frames at a time. Imaging was performed with a pair of 12-bit Photron SA5 cameras at 10 $\mathrm{kHz}$, at a resolution of $896 \times 848$ pixels, equipped with an $f=100 \mathrm{~mm}$ AT-X M100 Tokina lens set to an $\mathrm{f}$-number, $f / D$, of 11, and a final resolution of approximately $70 \mu \mathrm{m} /$ pixel. A band-pass filter centered at $527 \mathrm{~nm}$, with $4 \mathrm{~nm}$ full width at half maximum (FWHM), was used to reject flame emission. The cameras were installed in a side-scatter configuration and were angled at about 45 degrees relative to the laser sheet to provide equal displacement sensitivity in-plane and out-of-plane due to the high swirl number, $S_{\mathrm{m}}$, of the flow (see Figure 3). Scheimpflug adaptors were used to align the focal plane of the angled cameras to the measurement plane. Table 2 lists the imaging optics settings and specifications. 


\subsection{High Speed OH/fuel-PLIF Setup}

A dual-pulsed solid state Nd:YAG laser was operated at $5 \mathrm{kHz}$, with $5 \mathrm{~mJ}$ pulse energy, to pump a Sirah Credo tunable dye laser, which was then frequency-doubled to yield a UV pulse energy of $300 \mu \mathrm{J}$. The $\sim 566 \mathrm{~nm}$ output of the dye laser has a specified line width of $0.08 \mathrm{~cm}^{-1}$, thus the frequency-doubled output linewidth is $\sim 0.11 \mathrm{~cm}^{-1}$. The UV excitation was tuned to the $\mathrm{OH} \mathrm{Q}_{1}(6)$ transition of the $(1,0)$ vibrational branch in the $A-X$ system using a test burner, corresponding to a wavelength of $282.93 \mathrm{~nm}$. The Q- branch provides strong fluorescence signals, and the $\mathrm{Q}_{1}(6)$ line has a weak temperature dependence. The PLIF sheet was aligned to the sPIV sheet, and had the same span, but was about $100 \mu \mathrm{m}$ thick. The laser sheets were coincident to better than $1 / 4$ of the PIV sheet thickness, or $0.5 \mathrm{~mm}$.

The imaging cameras (12-bit Photron SA1 and NAC GX-3) were coupled to a high speed image intensifier and placed normal to the laser sheet on either side of the rig, see Figure 3a for a schematic and Figure $3 \mathrm{~b}$ for a photograph. Note the cylindrical polar coordinate system $(r, \theta, z)$ established in the figure. The intensifier allows for the collection of the UV light while also providing gating control to minimize interference from flame emission. An $f=45 \mathrm{~mm}, f / D=1.8$, UV camera lens was attached to each intensifier, and spectral filters were placed in front of each lens to maximize signal separation, while rejecting the excitation wavelength. The approximate resolution of the camera systems are $117 \mu \mathrm{m} /$ pixel for camera C3 and $68 \mu \mathrm{m} /$ pixel for C4. Table 2 lists the imaging optics specifications and settings.

The spectral separation of the fluorescence signals is illustrated in Figure 4. As shown, the laser excitation is narrow-band $\left(\sim 0.11 \mathrm{~cm}^{-1}\right)$, most of the $\mathrm{OH}$ fluorescence is concentrated within a $15 \mathrm{~nm}$ band, centered around 308 $\mathrm{nm}$, corresponding to the $(0,0)$ vibrational band, and the fuel fluorescence is broad, coinciding with the $\mathrm{OH}$ and extending well into the visible range. A $40 \mathrm{~nm}$ FWHM bandpass filter, centered at $320 \mathrm{~nm}$ was used in conjunction with a $15 \mathrm{~nm}$ FWHM bandpass filter, centered at $315 \mathrm{~nm}$ to optimize $\mathrm{OH}$ imaging. The narrower filter had significant transmission into the visible spectrum (above $550 \mathrm{~nm}$ ) and, thus, required use of the broader filter in series. A $305 \mathrm{~nm}$ Schott glass long-pass filter was used to reject only the excitation light and optimize for the fuelemission. Since the fuel-emission was much brighter than the OH-PLIF, rejection of the OH-fluorescence band was not required. The fuel emission camera captured some emission from the quartz tube in the form of horizontal lines, which are easily subtracted in image pre-processing.

The OH- and fuel-PLIF cameras used different intensifier gate settings as illustrated in Figure 5, to achieve temporal separation by taking advantage of the longer lived fuel fluorescence relative to shorter lived $\mathrm{OH}$ fluorescence. As the excitation duration ( 10ns) is on the same order of magnitude as the fluorescence lifetime, and there is overlap between the time of fluorescence and excitation, the intensifier gate opened shortly before the laser pulse. To maximize OH-PLIF, the intensifier gate closed as early as possible without cutting off the $\mathrm{OH}(\sim 10 \mathrm{~ns}$ after the laser pulse center) in order to avoid signal from the fuel-PLIF tail. For the fuel-PLIF imaging, the intensifier gate was ended $30 \mathrm{~ns}$ after the laser pulse center in order to capture all of the fuel fluorescence. Both gates were $40 \mathrm{~ns}$ long. Note in Figure 5 that the significant portion of the intensifier gates ahead of the laser pulse has no effect on the fluorescence and was required due to the minimum gate duration limit of the intensifiers $(\sim 40$ ns). 
While the strategies discussed above are designed to minimize the fuel-PLIF captured in the OH-PLIF images, it is impossible to eliminate the capture of fuel-PLIF in these images. Therefore, we refer to the images from the $\mathrm{OH}-$ PLIF imaging system as $\mathrm{OH}+$ fuel images. As discussed later in the paper, we used post-processing techniques (informed by the fuel-PLIF images) to identify the fuel-PLIF from the OH-PLIF + fuel-PLIF images.

\section{Data Reduction}

This section describes the OH/fuel-PLIF signal separation procedure. Due to intrinsic non-linearity in the response of the intensifiers, especially with brighter signals, combined with temporal and spatial variations in the fuel emission spectrum, the fuel image cannot be directly subtracted from the $\mathrm{OH}+$ fuel image. As such, a more involved procedure is needed to differentiate fuel and $\mathrm{OH}$ signals. We use the fuel-PLIF to instantaneously identify regions of liquid fuel, which is then used to mask those from the OH-PLIF + fuel-PLIF camera images. We start with synchronized images from the mixed OH-PLIF + fuel-PLIF camera and the fuel-PLIF camera.

First the images from the two flame imaging cameras are corrected for the camera/intensifier/lens system response and laser sheet profile by beginning with a raw image from each camera: (1) dark image subtraction to compensate for the camera sensor offset at zero light; (2) flatfield correction for spatial variation in the optical system intensity response; (3) time-averaged laser sheet intensity correction using acetone-PLIF; (4) image registration and LaVision's self-calibration on PIV and PLIF cameras. Note that we do not correct for the absorption of the laser along its beam path. As also noted by Frank et al. in a series of OH-PLIF measurements in a liquidfueled combustor at high pressure [22], the bottom halves of the $\mathrm{OH} /$ fuel emission images are significantly dimmer due to absorption of the laser energy (Frank et al. noted how this varied with pressure and fuel/air ratio). Consequently, the analysis here is confined to the top halves.

$\mathrm{Next}$ the fuel and $\mathrm{OH}+$ fuel images are post-processed to produce composite images revealing regions of $\mathrm{OH}$, fuel and overlapping $\mathrm{OH}$ and fuel:

1. Noise reduction: $6 \times 6$ pixel median filter applied twice to the fuel and $\mathrm{OH}+$ fuel images for noise reduction while preserving the edges.

2. Extraction of fuel-PLIF intensity thresholds: An intensity histogram of the fuel-PLIF image (computed from the entire top half of the interrogation plane) computed for all frames of a given run is shown in Figure 6. The histogram reveals two distinct populations, one corresponding to a weak background signal, and one corresponding to the liquid fuel emission signal. These different populations can be seen more readily from the lower figure which plots the derivative. In order to ensure that these different regions were not due to fundamentally different instantaneous images, histograms were also computed for smaller number of images which showed similar behaviors. The histograms of the fuel images from all cases look qualitatively similar to the histogram shown in Figure 6 (case 1 at 2.1 bar). We speculate that the multimodal distribution of the "signal" portion of the fuel histograms is linked to the atomization physics of the spray. Namely, the weaker signal population derives from a distribution of fine droplets with diameters smaller than the resolution of the imaging system (e.g., multiple small droplets in a given pixel), which cannot be resolved by the imaging system, while the stronger signal originates from a distribution of larger droplets or ligaments, which are readily resolved. Two thresholds are defined which appear naturally from the inflection points of the histogram, as shown in Figure 6. We call the first one the "background cut-off" and the second one the "signal cut-on".

The detectable fuel-PLIF signal corresponds to liquid fuel. The vapor fuel-PLIF is much dimmer and cannot be detected, mostly due to the difference in density. To illustrate this, we assume that the liquid and vapor fuel have a low absorption so that there are no laser depletion effects. We further assume that the vapor fuel has similar absorption and fluorescence yield as the liquid, i.e. the vapor is not undergoing pyrolysis which could change those properties. Fluorescence scales linearly with the number of molecules, but inversely with the quenching. For example, the highest possible pure gaseous to pure liquid fuel density ratio for the cases considered here is about $2 \%$. Regions of pure liquid are observed where there are fuel ligaments close to the nozzle lip. Quenching in the gas phase is higher, which reduces the gaseous fuel-PLIF yield, so that PLIF from gaseous fuel is lower than $2 \%$ of an equivalent volume of liquid fuel. Therefore, vapor fuel-PLIF does not register on the camera within the noise/background level of 10\% of full scale for our 12-bit camera as shown in Figure 6 for case 1. The conclusion that the fuel-PLIF images are dominated by liquid fuel (and fuel vapor is negligible) similarly extends to all other cases.

3. Composite image construction: Next the information from $\mathrm{OH}+$ fuel and fuel-PLIF is combined into composite images. This process is illustrated in Figure 7. Using the thresholds obtained above from the fuel-PLIF image, we identify three regions within the $\mathrm{OH}+$ fuel camera field: 
a) Intensity is less than the "weak cut-off", so there is no detectable fuel on the fuel-PLIF camera. Therefore any signal on the $\mathrm{OH}+$ fuel camera is from $\mathrm{OH}$.

b) Intensity is greater than the "weak cut-off" threshold, but less than the "strong fuel signal cut-on" threshold. Here the technique cannot distinguish between $\mathrm{OH}$ and small fuel droplets (fuel "mist"). We hypothesize that these regions represent small fuel droplets in a bath of $\mathrm{OH}$, or for short "fuel + OH."

c) Intensity is greater than the "strong fuel signal cut-on" threshold. Therefore, any signal in this region on the $\mathrm{OH}+$ fuel camera is dominated by fuel. Furthermore, the presence of resolved liquid fuel droplets and ligaments precludes the presences of $\mathrm{OH}$. We conclude there is fuel only in this region.

We construct composite false color images as in Figure 7 showing the "fuel only" in red, the "fuel + $\mathrm{OH}^{\text {" region in }}$ purple, and "no detectable fuel" in blue. To check the sensitivity of these levels, we computed and compared the thresholds for light spray frames (one standard deviation dimmer than average) and heavy spray frames (one standard deviation brighter than average). The resulting "fuel only" and "elevated $\mathrm{OH}^{\text {" thresholds were within } 1 \mathrm{~mm}}$ of each other on the flame images, while the "no detectable fuel" thresholds were within $3 \mathrm{~mm}$ of each other.

4. $\mathrm{OH}$ containing regions and flame location: In order to extract information about the flame location we examine relative signal values from the masked OH-PLIF images (i.e., the region outside the "weak cutoff", shaded in blue in Figure 12). Although the masked OH-PLIF images are not intended to provide $\mathrm{OH}$ concentrations, the histograms clearly indicates three different regions:

a) Background emission signal

b) Spatially diffuse, low level $\mathrm{OH}$ signal, predominantly found in the inner/outer recirculation zone (IRZ/ORZ) regions, and suggest that they originate from $\mathrm{OH}$ in recirculating product gases. These signal levels are roughly three times higher than the background.

c) Elevated $\mathrm{OH}$ in regions. These elevated $\mathrm{OH}$ levels occur immediately outside the fuel jet and in plumes downstream of the flame zone which appear to be closely associated with the super-equilibrium $\mathrm{OH}$ in and downstream of reaction zones. The background subtracted signal levels are roughly twice the low level $\mathrm{OH}$ levels.

We note that lower part of the histogram, including the low level $\mathrm{OH}$, are affected by the masking of the images as some $\mathrm{OH}$ is contained in the overlapping (purple) region and not retained by the masking. The elevated $\mathrm{OH}$ regions are defined from the inflection point shown in Figure 8 for case 1. As shown in Figure 8(b), the histogram shows three sub-population distribution peaks, corresponding to the three signal levels above. Again, the results are similar across all cases. Note that the ratios between the three signal levels noted above can be extracted from the histogram. As seen in Figure 8(b), a first-derivative local maximum identifies the cut-on point of the elevated $\mathrm{OH}$ level population. This threshold, shown in Figure 7 is later used to binarize masked OH-PLIF fields.

The signal-to-noise ratio (SNR) was calculated to be about 100 for the fuel signal in the fuel camera, and about 30 for the $\mathrm{OH}$ signal in the $\mathrm{OH}+$ fuel camera. The ratio was computed for a few representative frames as the mean over RMS, for a region of interest selected in a region of the camera view where the signal fuel/OH distribution appeared uniform. Since the laser UV output was modest, with pulse energies of $300 \mu \mathrm{J}$, we anticipate higher SNR ratios can be achieved with higher pulse energies.

Lastly, the processed fuel-PLIF images and weak cut-off threshold, as illustrated in Figure 7, are used to separate the PIV vectors into those representing the gas or liquid/droplet velocities. As discussed in the introduction, this is necessary because large droplets may not follow the flow and so estimates of gas phase velocity that do not account for this may have bias errors. To estimate the minimum detectable liquid droplet diameter, we assume again that the liquid and vapor fuel have similar low absorptivity and similar fluorescence gains. The low absorptivity assumption allows us to ignore laser energy depletion. Then we compute the ratio of the fuel fluorescence camera detectable fuel signal level to the full scale level, where full scale corresponds to $100 \%$ liquid corresponding to large ligaments near the nozzle. We use that ratio to estimate the volume of the smallest detectable spherical droplet by scaling the volume of the interrogation volume defined by the region of interest in physical space of a camera pixel multiplied by the laser sheet thickness. For example, the smallest detectable droplets are estimated to be $\sim 45 \mu \mathrm{m}$ in diameter, for which equations 24b and 25 from Mei [43], compute a cutoff frequency based on 50\% energy following for 450 $\mathrm{K}$ air as $54 \mathrm{~Hz}$. Finally, we check the sensitivity of our full scale intensity calibration. If what we assume to be $100 \%$ liquid is $10 \%$ liquid, the droplet diameter estimate would be smaller by $10^{1 / 3}$ or $\sim 21 \mu \mathrm{m}$.

To illustrate the separation process, the blue region in Figure 7 is used as a gas phase mask, and the red region as a spray mask, while data in the purple region is not used. The velocity vector extracted from each interrogation window is then binned into gas or liquid phase, resulting in two non-equally spaced velocity time series in each interrogation window. Depending upon spatial location, the relative fraction of velocity values binned as either gas or liquid phase varies significantly. Therefore, different regions of the averaged fields have different number of 
realizations, and we have removed time-averaged vectors with fewer than 100 realizations ( $2 \%$ of the total timeseries) in order to reject noise.

To close this section, it is important to discuss the sensitivity of the ensuing results to the thresholding approach, as well as the robustness of the inferred flow structures to these values. This was a question that we devoted significant attention to. As noted above, we computed and compared the thresholds for different populations of systematically different kinds of images - light spray frames (one standard deviation dimmer than average) and heavy spray frames (one standard deviation brighter than average). The resulting thresholds were within 1-3 mm of each other on the flame images. Moreover, we performed significant comparisons of the results where threshold values were systematically increased and decreased by up to $30 \%$. The basic structure of the spray and flame location discussed above are quite robust to any reasonable variation of these parameters. As might be expected, the location of "detectable spray" is most sensitive to these variations, while the location of "fuel only" is the least sensitive.

\section{Results}

We next present results illustrating the basic flow features and flow physics using these simultaneous velocity and scalar data. As noted above, PLIF images are only shown for the upper half of the flow.

\subsection{General Features}

Consider first basic flow features. Figure 9 illustrates key swirl flow features, along with characteristics of the spray and $\mathrm{OH}$ distribution. As illustrated in Figure 7, the red shading denotes fuel only, with signal coming from large droplets and ligaments, while the blue shading outside of the second black contour is signal from $\mathrm{OH}$. The region between the two black contours is shaded purple, as also illustrated in Figure 7, where small fuel droplets and $\mathrm{OH}$ coexist and fuel/OH cannot be differentiated with this technique. From this figure, various features can be noted in the flame and flow that are of interest, including: (1) degree of fuel spray penetration, (2) swirling annular jet flow, (3) outer recirculation zone (ORZ), (4) elevated OH level outside and the annular jet, (5) helical vortex shedding from the nozzle shear layers (6) internal recirculation zone (IRZ) and centerline reverse flow, and (7) low $\mathrm{OH}$ level inside the annular jet, in the IRZ.

Additional instantaneous results for this case are shown in Figure 10 as a filmstrip of 6 consecutive frames 200 $\mu$ s apart. Each frame consists of part (a): two components of PIV, $U_{z}=0$ line in green, and the regions of $\mathrm{OH}$, fuel, and $\mathrm{OH}+$ fuel; and part (b): all components of PIV with the out-of-page component color coded, and the $U_{\theta}=0$ line in black. In this sequence, the highly dynamic nature of the spray is evident. The helical vortex noted in Figure 9 advects axially as the 3-D vortex structure rotates and passes through the laser sheet. By comparing the images, flapping of the annular jet and spray is evident as well. The sPIV reveals that the swirling, out-of-plane velocity is highest in this annular jet region, similar to the axial velocity, indicating that the jet edges are regions of high shear in both the azimuthal and axial directions. The region of overlap between spray and $\mathrm{OH}$ is fairly wide compared to the region of pure spray (and no OH). The OH-PLIF (blue) signal is concentrated outside of the annular jet, in the ORZ. Note, as mentioned before, the presence of both elevated $\mathrm{OH}$ signal regions in certain regions (e.g., right outside the fuel jet and downstream of it in the annular jet), as well as a more diffuse background. This elevated $\mathrm{OH}$ region is likely the super-equilibrium $\mathrm{OH}$ present in the reaction and recombination zone, while the diffuse background is likely near equilibrium $\mathrm{OH}$ in the combustion products. Laminar flame CHEMKIN OPPDIFF calculations for decane at $5 \mathrm{bar}, \mathrm{T}_{\mathrm{ph}}=450 \mathrm{~K}$, and $\phi=0.7$, show that the $\mathrm{OH}$ mole fraction peaks to a value about $4.5 \mathrm{X}$ its equilibrium value, and the $\mathrm{OH}$ recombination zone is at least 20 times thicker than the heat release zone. This suggests that it is reasonable to spatially resolve regions of super-equilibrium $\mathrm{OH}$ for the present conditions; thus, we conclude that the highest concentrations of $\mathrm{OH}$ measured here represent reaction zone super-equilibrium $\mathrm{OH}$. Note the structure of the elevated $\mathrm{OH}$ regions which forms a plume downstream of the liquid jet. Both small scale and large scale rollup of the edges of these plumes is evident in the images. Note the pocket at the end of the liquid jet with no $\mathrm{OH}$, presumably consisting of (un-burned) air.

A film strip of instantaneous images from case 3 , which is at a higher pressure and $\phi$ relative to case 1 is shown in Figure 11. Again, both the spray and flowfield are highly unsteady. One important difference relative to the above case is that there is flame now on both sides of the jet, vs. only on the outside for case 1. Instantaneous filmstrips for three more cases, including the one with C-5 fuel are presented in Appendix B.

Various time-averaged measures can be used to define quantitative metrics for the flow, spray, and flame. However, direct averaging of the scalar PLIF fields is not useful, as it is not entirely clear that the actual quantitative values of the $\mathrm{OH}$ fields are meaningful, or what the averages would be useful for. Therefore, we focus on probability fields, obtained by defining a threshold to binarize the field, and then averaging the instantaneous binarized fields. Figure 12 presents the time-averaged gas phase velocity field, as well as fuel spray $\bar{p}_{1}=0.5$ and $\bar{p}_{2}=0.5$ lines, and 
a few $\bar{p}_{O H, \text { elev }}$ lines. $\bar{p}_{1}$ is the probability field for detectable fuel spray, obtained by binarizing the instantaneous field into values of unity for intensities above the weak fuel cut-on threshold (from Figure 6 and Figure 7) and zeros elsewhere, and averaging the binarized images. The $\bar{p}_{1}=0.5$ line (purple) corresponds to $50 \%$ probability of finding detectable fuel. This line can also be thought of as an $\mathrm{OH}$ boundary; i.e., there is predominantly $\mathrm{OH}$ outside. Similarly, $\bar{p}_{2}$ is the probability field for finding fuel spray only, see Figure 12b, obtained by averaged binarized fuel images assigned ones for intensities above the strong fuel threshold and zeros elsewhere. The $\bar{p}_{2}=0.5$ line (red) corresponds to $50 \%$ probability of finding fuel spray only. Although the $\bar{p}_{1}$ and $\bar{p}_{2}$ probability fields are indicative of the fuel evaporation, they are also affected by the unsteady motion of the spray. In other words, strong flapping of the spray will cause separation of iso- $\bar{p}_{1}$ and $\bar{p}_{2}$ values. Note that there is some $\mathrm{OH}$ in the region between $\bar{p}_{1}=0.5$ and $\bar{p}_{2}=0.5$, and its thickness is related to the distance between the flame and the bulk of the spray, as well as the unsteady motion of the spray. Finally, $\bar{p}_{O H}$ (blue lines) is the probability field for elevated $\mathrm{OH}$ levels.

Figure 12a overlays several of these time averaged quantities in order to provide a picture of the reacting flow structure. Several scalar values are shown indicating the region where pure fuel, detectable fuel, and elevated $\mathrm{OH}$ exist - the $\bar{p}_{1}=0.5$ (purple), $\bar{p}_{2}=0.5$ (red), and a few $\bar{p}_{\text {OH,elev }}$ (blue) lines. The structure of the flow field is shown by indicating the time-averaged in-plane components of gas phase PIV ( note some blanked regions in the fuel only region, for the reasons indicated in the "Data reduction" section on separating PIV into gas phase and liquid phase), the axial velocity stagnation line, $U_{z}=0$ (green), the jet core (locus of maximum velocity magnitude) in a dashed black line, and inner and outer shear layers (ISL and OSL, respectively, defined as the locus of maximum out-ofplane component of vorticity) in black. Several observations can be made from this combined picture. First, note that, for this case, elevated OH is predominantly found outside of the OSL, in the ORZ; i.e., not in the IRZ (this is not always the case as shown later). As seen in the instantaneous frames from Figure 10, OH is detected inside of the ISL as well as along the annular jet, although not at these elevated levels for this case, but we will show other cases in which there are elevated levels of $\mathrm{OH}$ in the jet. The lower levels of $\mathrm{OH}$ are likely associated with the recirculating combustion products in the IRZ, and not indicative of a reaction front. The annular jet spreading is evident from the jet core. The jet core lines are almost identical for the cases 1 through 5 shown here, and so are not plotted. The dotted $U_{\mathrm{z}}=0$ line shows the recirculation bubble boundary, and also does not vary much across cases. The $\bar{p}_{2}=0.5$ contour penetrates about $0.49 D_{0}$, and the $\bar{p}_{1}=0.5$ contour lies outside of that. Note also the location of the spray and elevated $\mathrm{OH}$ with respect to the key flow features. Specifically the "detectable fuel" and "fuel only" regions lie between the jet core and outer shear layer; i.e., they are in the annular jet column but on the outside. This is consistent with the picture for these filming type injectors shown in Figure 1 (right).

In order to illustrate the distribution of the spray probability values, Figure $12 \mathrm{~b}$ plots iso- $\bar{p}_{2}$ values for $0.1,0.2$ and 0.5 , and the "detectable fuel" $\bar{p}_{1}=0.5$ contour. It shows that the 0.1 and $0.2 \bar{p}_{2}$ isocontours are located as expected between the $\bar{p}_{1}=0.5$ and $\bar{p}_{2}=0.5$ lines of Figure 12a. The exact spacing and shape of these lines changes with fuel type and operating conditions as the fuel evaporation rate and vapor distribution are modified. The liquid phase velocity field is plotted in Figure 12b in order to enable comparison with the gas phase velocity field. Recall that vectors are shown only in locations with more than 100 realizations, so there are no vectors shown outside of a given region, which happens to roughly follow the no fuel $\bar{p}_{1}=0.5$ line. The liquid PIV is not drastically different than the gas-phase PIV. The key differences between the velocity fields is that the liquid PIV field shows a higher spreading angle along the outermost radial location, and a lower spreading angle along the innermost radial location.

In order to relate these features to the out of plane velocity, Figure $12 \mathrm{c}$ plots the time-averaged azimuthal velocity component using a color bar along with the $U_{\theta}=0$ line in black. The $U_{\theta}=0$ line is along the centerline, as expected, for an axisymmetric time-averaged flow.

The rest of the results section is organized into three more sub-sections, discussing the spray distribution, flame shape, and the nature of flame stabilization across the various conditions.

\subsection{Spray distribution}

The spray distribution is sensitive to preheat temperature, nozzle air velocity, fuel flow rate, pressure, and fuel composition. The spray distribution responds noticeably to changes in these quantities across test conditions. Note that the jet core and shear layers across the different cases are virtually identical, so results are only shown for one case. This also shows that the shifts in spray position and $\mathrm{OH}$ field discussed next are not due to changes in the time averaged gas flow field. 
Figure 13a enables comparison of cases 1, 3 and 5, representing our three operating pressures. We note that the fuel spray lines $\bar{p}_{2}=0.5$ and $\bar{p}_{1}=0.5$ are almost identical between case 1 and 3 , although the pressure is about $75 \%$ higher and the fuel flow is increased as indicated by the higher $\phi$. The $\bar{p}_{2}=0.5$ fuel spray contour for case 3 extends about $0.44 D_{0}$, which is very similar to the $0.49 D_{0}$ for case 1 despite the higher fuel/air ratio of $0.61 \mathrm{vs.} 0.38$ and elevated pressure of 3.4 vs. 2.1 bar. Also evident in Figure 13a is that the detectable fuel $\bar{p}_{1}=0.5$ lines are the same for cases 1 and 3 .

The further increase in pressure and slight decrease in $\phi$ in going from case 3 to 5 results in the $\bar{p}_{2}=0.5$ line shifting upstream and penetrating axially $0.29 D_{0}$. The $\mathrm{OH}$ boundary $\bar{p}_{1}=0.5$ line is significantly closer to the $\bar{p}_{2}=0.5$ fuel spray line, and extends only $0.59 D_{0}$, relative to larger $0.84-0.88 D_{0}$ values for the lower pressure cases. If increased fuel flow generally pushes the spray outward, it seems that increasing pressure brings the spray in, although the jet flapping may be different between the two cases and affecting the spray.

Figure $13 \mathrm{~b}$ overlays $\bar{p}_{1}=0.5$ and $\bar{p}_{2}=0.5$ lines for cases 3 and 4 . Everything else being equal, we expect the higher preheat case 4 to show faster evaporation by having a recessed fuel spray $\bar{p}_{2}=0.5$ line. Instead, we observe the $\mathrm{OH}$ boundary line $\bar{p}_{1}=0.5$ shifts axially downstream, from 0.84 to $0.98 D_{0}$, and radially, from 0.74 to $0.93 D_{0}$, and the fuel spray only $\bar{p}_{2}=0.5$ line also move out from 0.44 to $0.59 D_{0}$. Apparently, this result is a manifestation of competing effects as we simultaneously increase the preheat temperature and nozzle velocity: First, although the fuel spray only $\bar{p}_{2}=0.5$ line moves outward, the closer spacing between fuel spray only $\bar{p}_{2}$ isolines, i.e. $\bar{p}_{2}=0.5$ and 0.1 lines (not shown for brevity but similar to Figure 12b), indicates the fuel is evaporating faster (an alternative explanation, of course, is that the liquid jet column is flapping less). Second, the faster evaporation likely produces a fuel-rich gas mixture, pushing out the $\mathrm{OH}$ boundary $\bar{p}_{1}=0.5$ line as observed. Third, the higher nozzle velocity would also push the spray and flame outward.

Figure $13 \mathrm{~b}$ also plots the fuel spray $\bar{p}_{1}=0.5$ and $\bar{p}_{2}=0.5$ lines, and shear layers for case 2 with the lower boiling point C-5 fuel. In case 2 the global $\phi$ is much lower, combined with a more volatile fuel resulting in much less spray. As expected, the fuel spray $\bar{p}_{1}=0.5$ and $\bar{p}_{2}=0.5$ lines move inward relative to cases 3 and 4 .

\subsection{Flame shape}

Prior work [44] in gaseous premixed flows shows that multiple flame topologies may exist in swirl flows of this nature, with the flame attaching itself to the ISL/OSL of the nozzle, or with the flame stabilized aerodynamically in the center of the flow by vortex breakdown. In the present work we use super-equilibrium $\mathrm{OH}$ levels to indicate the flame location. We observe two flame configurations. The first one (Type I) appears for the low $\phi$, low preheat temperature cases 1 and 2, with a flame wrapped around the outside of the OSL. In other words, we hypothesize that the $\mathrm{OH}$ in the center is not indicative of reactions, but instead is indicative of recirculating products. Note that case 2 is the only one with C-5 fuel, and fuel composition may be playing a role here. The second configuration (Type II) appears at higher $\phi$ and preheat temperature, with a flame appearing both outside of the OSL and around the inside of the ISL. The sensitivity of the flame shape to preheat temperature and equivalence ratio is illustrated in Figure 15 for all cases. Figure 15a plots this sensitivity against preheat temperature and Figure 15b against the combustion pressure, illustrating that the effect is dominated by change in equivalence ratio, although it is possibly also affected by preheat temperature and pressure.

These observations are illustrated using instantaneous frames comparing case 1 from Figure 10 with case 3 in Figure 11. The frames in Figure 10 from case 1 reveal very weak or even complete lack of OH-PLIF in the inside of the IRZ or in the center of the flow. In contrast, the frames from Figure 11 show super-equilibrium $\mathrm{OH}$ in both the ORZ and IRZ.

The observations on flame shape from instantaneous data are supported by time-averaged data. Figure 14 compares the time-averaged data for cases 1 and 3. In particular the $\bar{p}_{O H, \text { elev }}$ fields indicate the flame shape, and show a flame predominantly in the ORZ for case 1 and a flame in both the ORZ and IRZ for case 3.

\subsection{Flame stabilization}

This section considers the most upstream points where combustion occurs and compares and contrasts them between spray flames and premixed flames. Chterev et al. [45] previously reported data using this identical nozzle, but with premixed methane/air as fuel. In order to achieve uniform premixing, the fuel injection holes were not used in that study, and the fuel and air were mixed $2.0 \mathrm{~m}$ upstream of the nozzle. As the axial and radial distribution of heat release has such profound influences on combustor behavior, it is useful to reflect on the differences between the uniformly premixed flame reported previously and this spray flame. 
As discussed by Chterev et al. [45], premixed flames encountered in annular jet configurations like this have multiple configurations depending upon whether the flame is stabilized in the inner or outer shear layers of the annular jet, or is aerodynamically stabilized at interior stagnation points. From these stabilization regions, flames then propagate into the reactant jet core, at an angle controlled by the ratio of turbulent flame speed and flow velocity. PIV/OH-PLIF data from the present nozzle show that the flame has an "M-shape" and stabilizes near the outer shear layers and partially in the inner shear layers and vortex breakdown bubble. This is shown in Figure 16 with a time-averaged velocity field and with a $\bar{p}_{O H, \text { elev }}=0.5$ contour (blue). This iso- $\bar{p}_{O H, \text { elev }}$ line is determined in an analogous manner as in this liquid fuel study; i.e., by averaging intensity binarized OH-PLIF images, in which value of one corresponds to regions with elevated $\mathrm{OH}$ and a value of zero is defined elsewhere. The intensity threshold is determined in a similar way but much more straight forward way as the fuel and OH-PLIF thresholds discussed here, since the flowfield either does or does not have $\mathrm{OH}$. Since the instantaneous isolines indicate the reaction zone for this premixed system, the $\bar{p}_{O H \text {,elev }}=0.5$ isoline in Figure 16 represents the time-averaged reaction zone location.

Comparing the $\bar{p}_{O H, \text { elev }}=0.5$ isolines in Figure 14 and Figure 16 shows some significant differences. In the premixed case, the flame originates in the low velocity shear layers and/or recirculating flow regions, as expected. Similarly, the outer spray flame originates in the OSL, also near the indicated shear layers. In contrast, looking at all the spray flame results for cases where Type II flames are observed, note that the inner flame always originates in the high velocity jet core itself (e.g., see cases 3 and 5 in Figure 13, or the better view of case 3 in Figure 14). This would not happen in a premixed combustion system as the velocity inside the jet is too high relative to the turbulent flame speed. Rather, these results starkly illustrate the different controlling physics for flame location between the premixed case and spray flame - the spray flame sits right outside of the spray. As the outside of the spray is nearly coincident with the outer shear layer, the flame is also fortuitously coincident with the shear layer. However, the fact that the inside edge of the spray is well inside of the jet core allows us to differentiate the relative roles of the shear layer and spray placement, as the flame is clearly inside of the jet core. In contrast, as premixed flames stabilize via a propagating mechanism, they will originate in low velocity regions.

\section{Concluding Remarks}

This work has demonstrated time-resolved $(5 \mathrm{kHz})$ combined OH-PLIF, fuel-PLIF and stereo-PIV in high pressure, reacting, Jet-A and C-5 spray, in a swirl stabilized combustor. A single dye laser is used to excite both the $\mathrm{OH}$ and fuel, and the signals are separated spectrally and temporally using two cameras and intensifiers. Intensity histograms are used to extract thresholds, which are used to identify regions of fuel, $\mathrm{OH}$, and a mixture of fuel and $\mathrm{OH}$. Sensitivity analyses demonstrate that the key results and conclusions from this study are unaltered by data reduction parameters such as thresholds.

In order to demonstrate the technique at multiple conditions, measurements were taken with Jet-A and C-5, (C5 has a lower boiling point, higher aromatics content, and lower viscosity), and at different $T_{\mathrm{ph}}=450 \mathrm{~K}$ and $570 \mathrm{~K}$, and pressures of 2.1, 3.5, and 5.2 bar. The resulting data enable simultaneous visualization of the flow field, spray, and flame location and enable a construction of key flow/flame features that are not possible to infer with a single measurement. At lower equivalence ratios, the flame exists only outside of the fuel jet in the ORZ, but increasing preheat temperature and equivalence ratio allows an M-shaped flame to exist in the IRZ as well. This observation, that multiple flame topologies are possible with the same fuel injector, was not unexpected and is well known for gaseous, premixed flames, but is nonetheless very significant. These different flame shapes would have different liner heat loading characteristics, combustion instability characteristics, and emissions characteristics.

A second important observation is the location of the flame with respect to the jet flow and fuel features. These data clearly show the flame originating in the high velocity core just outside of the spray - i.e., the flame follows the fuel. Again, while this observation is not necessarily surprising, it was noted that premixed flames are located in low velocity regions, and that the location of the flame in a premixed configuration with this geometry would have been quite different. Again, this observation has important implication on the flame location and axial heat release distribution.

An additional result of this work was the development of nonlinear averaging techniques, based upon thresholding of the inferred spray and flame locations, to develop progress field maps to elucidate the general structure of the flow, spray, and flame. Such progress field maps are useful for quantifying statistics about the relative locations of these three key quantities, and for reducing (but not replacing) a large set of time-resolved data into a reduced set of results, useful for both understanding flow physics as well as comparison of results with computations. 

particularly in flows with heavy levels of particulates. For example, many aircraft engine applications of the kind that motivated this work, actually operate with fuel-rich primary zones, and thus the flame and flow are often surrounded by a particulate cloud (e.g., see Schroll et al. [15] or Meier et al. [16]). Moreover, the ability to simultaneously resolve other key scalars, such as those indicative of fuel-decomposition, soot formation, and pollutant formation would be very enlightening, both from providing insights into controlling physics, as well as for comparison with and validation of time-resolved computations of reacting sprays. For example, the present set of results can be used to benchmark calculations of the flow field and basic flame position features, but additional measurements would be needed to validate spatio-temporal locations of soot or NOx formation.

\section{Appendix A: PIV Uncertainty}

Loss-of-particle image pairs error can be problematic in swirling flows due their three dimensional nature. If the laser sheet is along the central plane of the combustor, as in the present study, the swirling component of velocity is out-of-plane. We use a thick laser sheet in order to control the loss-of-pairs error. With a sheet thickness of $2.0 \mathrm{~mm}$, anticipated $S_{m}$ on the order of 1 , and nozzle velocity of $65 \mathrm{~m} / \mathrm{s}$, the loss-of-pairs due to out of plane motion is calculated to be less than about $50 \%$, which is the worst case scenario, at the nozzle exit. This value greatly improves away from the nozzle exit plane as the azimuthal velocity quickly decays. The sheet was not made any thicker because increasing its thickness has the following effects: (1) reduction of the signal-to-background ratio for the scattered light from a given particle; (2) reduction of the correlation values computed by the PIV algorithm as the larger interrogation volume captures eddies which result in more complicated particle shift patterns; (3) the outof-plane spatial resolution of the measurement decreases.

Note that in the raw PIV images most particles appear about 2-3 pixels in size, as a result of the optical system quality. It is important that particles are larger than 1 pixel to avoid pixel-locking error in the velocity computation, and to allow sub-pixel interpolation. Velocity resolution with LaVision's sub-pixel interpolation capability ( 0.1 of a pixel) is $0.45 \mathrm{~m} / \mathrm{s}$ given by the camera magnification of $72 \mu \mathrm{m} / \mathrm{pixel}$ and pulse separation of $16 \mu \mathrm{s}$. Axial velocity, $U_{\mathrm{z}}$, loss-of-pairs error is minimized by using multiple passes with decreasing interrogation window size, allowing much longer axial displacements than a single pass algorithm of a typical interrogation window size.

Radial velocity, $U_{\mathrm{r}}$, bias due to centrifugal forces is reduced by the relatively high preheat and further in the hot products, and by the use of the small 0.5-1.0 micron particles. Reference calculations for a simple annular swirler geometry can be found in ref. [44].

Following equations 24b and 25 from Mei [43], the cutoff frequency based on 50\% energy following for 0.5-1 micron particles, was calculated to be $4-17 \mathrm{kHz}$ for $450 \mathrm{~K}$ preheat. The lower value provides a conservative estimate to allow for some seeding particle clumping in the seeder. This values increases by a factor of more than 10 in the products due to the much higher kinematic viscosity. The macro time scale corresponding to the nozzle diameter and average axial nozzle velocity ranges from 180 to $310 \mu \mathrm{s}$ (5.5 to $3.2 \mathrm{kHz}$ ), corresponding to the fastest and slowest nozzle velocity. The Nyquist frequency of the PIV acquisition is $2.5 \mathrm{kHz}$.

\section{Appendix B: Instantaneous Data}

This appendix presents instantaneous results from additional test cases. Figure 17 shows some instantaneous frames for the highest pressure case 5; time averaged results from this case were presented in the main body. Figure 18 shows three frames from the high preheat case 4 at $T_{\mathrm{ph}}=570 \mathrm{~K}$. Relative to case 3 , the fuel/air ratios and operating pressures are the same within 5\%, while the nozzle velocity at the high preheat is $10 \%$ higher. The elevated $\mathrm{OH}-$ containing regions are larger. Figure 19 presents case 2, which is at the same pressure and preheat temperature as case 3, but with C-5 and at a lower global $\phi=0.38$ vs. 0.61 . C-5 has a notably lower $90 \%$ boiling point of $438 \mathrm{~K}$, relative to $518 \mathrm{~K}$ for Jet-A and should evaporate more quickly.

\section{Acknowledgments}

This work was obtained as part of a larger measurement campaign that was funded by the United Technologies Corporation, the US Federal Aviation Administration (FAA) Office of Environment and Energy as a part of ASCENT Project 27A under FAA Award Numbers: 13-C-AJFE-GIT-008 and 13-C-AJFE-UI-013, and the Air Force under AFRL Contract No. FA8650-13-C-2307. The subset of data presented here was obtained with financial support from United Technologies Corporation and the FAA. Any opinions, findings, and conclusions or recommendations expressed in this material are those of the authors and do not necessarily reflect the views of the FAA or other ASCENT Sponsors. 


\section{References}

[1] P. Petersson, J. Olofsson, C. Brackman, H. Seyfried, J. Zetterberg, M. Richter, M. Aldén, M.A. Linne, R.K. Cheng, A. Nauert, D. Geyer, Simultaneous PIV/OH-PLIF, Rayleigh Thermometry/OH-PLIF and Stereo PIV Measurements in a Low-Swirl Flame, Applied Optics 46 (2007) 3928-3936.

[2] J. Hult, U. Meier, W. Meier, A. Harvey, C.F. Kaminski, Experimental Analysis of Local Flame Extinction in a Turbulent Jet Diffusion Flame by High Repetition 2-D Laser Techniques and Multi-Scalar Measurements, Proc. Combust. Inst. 30 (2005) 701 709.

[3] A.M. Steinberg, J.F. Driscoll, S.L. Ceccio, Measurements of Turbulent Premixed Flame Dynamics Using Cinema Stereoscopic PIV, Exp. Fluids 44 (2008) 985-999.

[4] C. Arndt, A. Steinberg, I. Boxx, W. Meier, M. Aigner, C. Carter, Flow-Field and Flame Dynamics of a Gas Turbine Model Combustor During Transition Between Thermo-Acoustically Stable and Unstable States, Turbo Expo, ASME, Glasgow, UK, 2010.

[5] A. Steinberg, I. Boxx, M. Stöhr, W. Meier, C. Carter, Effects of Flow Structure Dynamics on Thermoacoustic Instabilities in Swirl-Stabilized Combustion, AIAA 50 (2012).

[6] A. Upatnieks, J.F. Driscoll, S.L. Ceccio, Cinema Particle Imaging Velocimetry Time History of the Propagation Velocity of the Base of a Lifted Turbulent Jet Flame, Proc. Combust. Inst. 29 (2002) 1897-1903.

[7] M. Tanahashi, S. Murakami, G.M. Choi, Y. Fukuchi, T. Miyauchi, Simultaneous CH-OH PLIF and Stereoscopic PIV Measurements of Turbulent Premixed Flames, Proc. Combust. Inst. 30 (2005) 1665-1672.

[8] M. Shimura, T. Ueda, G.M. Choi, M. Tanahashi, T. Miyauchi, Simultaneous Dual-Plane CH PLIF, Single-Plane OH PLIF and Dual-Plane Stereoscopic PIV Measurements in Methane-Air Turbulent Premixed Flames, Proc. Combust. Inst. 33 (2011) 775-782.

[9] B. Böhm, Heeger, C., Boxx, I., Meier, W., Dreizler, A., Time-resolved conditional flow field statistics in extinguishing turbulent opposed jet flames using simultaneous highspeed PIV/OH-PLIF, Proc. Comb. Institute 32 (2009) 1647-1654.

[10] R. Sadanandan, Stöhr, M., Meier, W., Simultaneous OH-PLIF and PIV measurements in a gas turbine model combustor, Applied Physics B 90 (2008) 609-618.

[11] B. Coriton, Steinberg, A. M., Frank, J. H., High-speed tomographic PIV and OH PLIF measurements in turbulent reactive flows, Exp. Fluids 55 (2014) 1743.

[12] A.M. Steinberg, Boxx, I., Arndt, C. M., Frank, J. H., Meier, W., Experimental study of flame-hole reignition mechanisms in a turbulent non-premixed jet flame using sustained multi-kHz PIV and crossed-plane OH PLIF, Proc. Comb. Institute 33 (2011) 1663-1672.

[13] C.T. Chong, S. Hochgreb, Spray Flame Study Using a Model Gas Turbine Swirl Burner, Applied Mechanics and Materials 316 (2013) 17-22.

[14] C.T. Chong, S. Hochgreb, Spray Flame Structure of Rapeseed Biodiesel and Jet-A1 Fuel, Fuel 115 (2014) $551-558$.

[15] M. Schroll, J. Klinner, L. Lange, C. Willert, Particle Image Velocimetry of Highly Luminescent, Pressurized Combustion Flows of Aero Engine Combustors, 10th Int. Symp. on Particle Image Velocimetry, Delft, Netherlands, 2013.

[16] U. Meier, J. Heinze, E. Magens, M. Schroll, C. Hassa, S. Bake, T. Doerr, Optically Accessible Multisector Combustor: Application and Challenges of Laser Techniques at Realistic Operating Conditions, Turbo Expo, ASME, Montreal, Canada, 2015.

[17] C. Slabaugh, A.C. Pratt, R.P. Lucht, Simultaneous $5 \mathrm{kHz}$ OH-PLIF/PIV for the study of turbulent combustion at engine conditions, Applied Physics B 118 (2015) 109-130.

[18] C. Slabaugh, I. Boxx, S. Werner, R.P. Lucht, W. Meier, Structure and Dynamics of Premixed Swirl Flames at Elevated Power Density, AIAA 54 (2016) 946-961.

[19] M.G. Allen, K.R. McManus, D.M. Sonnenfroh, P.H. Paul, Planar Laser-Induced-Fluorescence Imaging Measurements of $\mathrm{OH}$ and Hydrocarbon Fuel Fragments in High-Pressure Spray-Flame Combustion, Applied Optics 34 (1995) 6287.

[20] O.V. Roditcheva, X.S. Bai, Pressure Effect on Soot Formation in Turbulent Diffusion Flames, Chemosphere 42 (2001) 811 821.

[21] Z. Zhang, Q.A. Ezekoye, Soot Production Rate Calculations at Elevated Pressure in a Methane-Air Jet Diffusion Flame, Combust. Sci. Tech. 137 (1998) 323-346.

[22] J.H. Frank, M.F. Miller, M.G. Allen, Imaging of Laser-Induced Fluorescence in a High-Pressure Combustor, 37th ASME, 1999, pp. 773.

[23] R.J. Locke, Y.R. Hicks, R.C. Anderson, K.A. Ockunzzi, OH Imaging in a Lean Burning High-Pressure Combustor, AIAA 34 (1996) 622-624.

[24] Y.R. Hicks, R.J. Locke, R.C. Anderson, Optical measurement and visualization in high-pressure high-temperature aviation gas turbine combustors, Symp. Applied Photonics, Int. Society Optics and Photonics, 2000, pp. 66-77.

[25] S.A. Skeen, Manin, J. and Pickett, L. M., Simultaneous formaldehyde PLIF and high-speed schlieren imaging for ignition visualization in high-pressure spray flames, Proc. Comb. Institute 35 (2015) 3167-3174.

[26] A. Lantz, R. Collin, J. Sjöholm, Z.S. Li, P. Petersson, M. Aldén, High-Speed Fuel/Hydroxyl Radical Imaging in a Gas Turbine Pilot Burner, AIAA 50 (2012) 971-976.

[27] J. Hult, M. Richter, J. Nygren, M. Aldén, A. Hultqvist, M. Christensen, B. Johansson, Application of a High-Repetition-Rate Laser Diagnostic System for Single-Cycle-Resolved Imaging in Internal Combustion Engines, Applied Optics 41 (2002) $5002-$ 5014. 
[28] S.H.R. Müller, B. Böhm, M. Gleißner, S. Arndt, A. Dreizler, Analysis of the Temporal Flame Kernel Development in an Optically Accessible IC Engine Using High-Speed OH-PLIF, Applied Physics B 100 (2010) 447-452.

[29] B. Peterson, V. Sick, High-speed flow and fuel imaging study of available spark energy in a spray-guided direct-injection engine and implications on misfires, Int. J. Engine Research 11 (2010) 313-329.

[30] J.M. Seitzman, R.K. Hanson, Comparison of Excitation Techniques for Quantitative Fluorescence Imaging of Reacting Flows, AIAA 31 (1993) 513-519.

[31] B.E. Battles, R.K. Hanson, Laser-Induced Fluorescence Measurements of NO and OH Mole Fraction in Fuel-Lean, HighPressure (1-10 atm) Methane Flames: Fluorescence Modeling and Experimental Validation, Quantitative Spectroscopy and Radiative Transfer 54 (1995) 521-537.

[32] H. Kobayashi, Y. Oyachi, K. Maruta, LIF Measurements of Turbulent Premixed Flames in a High Pressure Environment, Joint Thermal Engineering Conference, ASME/JSME, 1999.

[33] G. Singla, P. Scouflaire, C. Rolon, S. Candel, Planar Laser-Induced Fluorescence of OH in High-Pressure Cryogenic LOx/GH 2 Jet Flames, Combust. Flame 144 (2006) 151-169.

[34] N. Jiang, Patton, R. A., Lempert, W. R., Sutton, J. A., Development of high-repetition rate CH PLIF imaging in turbulent nonpremixed flames, Proc. Comb. Institute 33 (2011) 767-774.

[35] M.N. Slipchenko, Miller, J. D., Roy, S., Gord, J. R., Meyer, T. R., All-diode-pumped quasi-continuous burst-mode laser for extended high-speed planar imaging, Optics express 21 (2013) 681-689.

[36] J.D. Miller, Slipchenko, M., Meyer, T. R., Jiang, N., Lempert, W. R., Gord, J. R., Ultrahigh-frame-rate OH fluorescence imaging in turbulent flames using a burst-mode optical parametric oscillator, Optics Letters 34 (2009) 1309-1311.

[37] C.T. Chong, S. Hochgreb, Flow Field of a Model Gas Turbine Swirl Burner, Advanced Materials Research 622 (2013) 1119-1124.

[38] A.M. Steinberg, Arndt, C. M., Meier, W., Parametric study of vortex structures and their dynamics in swirl-stabilized combustion, Proc. Comb. Institute 34 (2013) 3117-3125.

[39] S. Roy, Hua, J. C., Barnhill, W., Gunaratne, G. H., Gord, J. R., Deconvolution of reacting-flow dynamics using proper orthogonal and dynamic mode decompositions, Physical Review E 91 (2015).

[40] S. Roy, T. Yi, N. Jiang, G. Gunaratne, I. Chterev, B. Emerson, T. Lieuwen, A.W. Caswell, J.R. Gord, Dynamics of Robust Structures in Turbulent Swirling Flows, J. Fluid Mech. 816 (2017) 554-585.

[41] J.M. Cohen, T.J. Rosfjord, Influences on the Uniformity of Sprays Produced by gas Turbine High Shear Nozzle/Swirler Assemblies, 26th Joint Propulsion Conference, Orlando, FL, 1990, pp. 2193.

[42] M. Colket, J. Heyne, M. Rumizen, M. Gupta, A. Jardines, T. Edwards, W.M. Roquemore, G. Andac, R. Boehm, J. Zelina, J. Lovett, J. Condevaux, S. Bornstein, N. Rizk, D. Turner, C. Graves, M.S. Anand, R. Williams, F. Xu, J. Tishkoff, C. Li, J. Moder, R. Anthenien, D. Friend, P.Chu, R. Kamin, P. Serino, M. Domen, C.M. Kweon, V. Sankaran, J. Cohen, W. Chishty, An Overview of the National Jet Fuels Combustion Program, SciTech, AIAA, San Diego, California, 2016.

[43] R. Mei, Velocity Fidelity of Flow Tracer Particles, Exp. Fluids 22 (1996) 1-13.

[44] I. Chterev, C.W. Foley, D. Foti, S. Kostka, A.W. Caswell, N. Jiang, A. Lynch, D.R. Noble, S. Menon, J.M. Seitzman, T. Lieuwen, Flame and Flow Topologies in an Annular Swirling Flow, Combust. Sci. Tech. 186 (2014) 1041-1074.

[45] I. Chterev, B. Emerson, T. Lieuwen, Characterization of Aerodynamically Stabilized Flames using Simultaneous Analysis of Planar and Line-of-Sight Images, SciTech, AIAA, San Diego, CA, 2016. 
Table 1: Operating conditions.

\begin{tabular}{c|c|c|c|c|c} 
Case & $\boldsymbol{p}$ [bar] & $\begin{array}{c}\boldsymbol{T}_{\mathbf{p h}} \\
{[\mathbf{K}]}\end{array}$ & $\boldsymbol{\phi}$ & $\begin{array}{c}\text { Nozzle } \\
\text { velocity } \\
{[\mathbf{m} / \mathbf{s}]}\end{array}$ & Fuel \\
\hline 1 & 2.1 & 450 & 0.38 & 78 & Jet-A \\
\hline 2 & 3.7 & 451 & 0.38 & 65 & C-5 \\
\hline 3 & 3.4 & 446 & 0.61 & 78 & Jet-A \\
\hline 4 & 3.6 & 570 & 0.63 & 85 & Jet-A \\
\hline 5 & 5.2 & 459 & 0.47 & 75 & Jet-A \\
\hline 6 & 2.3 & 563 & 0.45 & 83 & Jet-A \\
\hline 7 & 1.7 & 572 & 0.65 & 112 & Jet-A \\
\hline 8 & 1.8 & 578 & 0.95 & 105 & Jet-A \\
\hline 9 & 5.1 & 577 & 0.49 & 88 & Jet-A
\end{tabular}


Table 2: Imaging optics specifications and settings.

\begin{tabular}{|c|c|c|c|c|c|c|c|}
\hline Function & Camera & Intensifier & $\begin{array}{l}\text { Intensifier } \\
\text { Gate }\end{array}$ & Lens & $\begin{array}{l}\text { Frame Rate/ } \\
\text { Resolution }\end{array}$ & f/D Setting & Spectral Filters \\
\hline sPIV, C1 & Photron SA5 & N/A & N/A & Tokina AT-X M100 100mm, f/D=2.8 & $\begin{array}{c}10 \mathrm{kHz} / 896 \times 8 \\
48 \text { pixels }\end{array}$ & 4.0 & Band-pass: 527/20 nm FWHM, T=97\% \\
\hline sPIV, C2 & Photron SA5 & N/A & N/A & Tokina AT-X M100 100mm, f/D=2.8 & $\begin{array}{c}10 \mathrm{kHz} / 896 \times 8 \\
48 \text { pixels }\end{array}$ & 4.0 & $\begin{array}{c}\text { Band-pass: } 527 / 2 \mathrm{~nm} \text { FWHM, } \\
\mathrm{T}=97 \%\end{array}$ \\
\hline Fuel-PLIF, C3 & NAC GX-3 & Lambert HiCATT $(25 \mathrm{~mm})$ & See Fig. 3 & Cerco, $45 \mathrm{~mm}, \mathrm{f} / \mathrm{D}=1.8$ & $\begin{array}{c}5 \mathrm{kHz} / 512 \times 72 \\
0 \text { pixels }\end{array}$ & 1.8 & $\begin{array}{l}\text { Long-pass: } 2 \mathrm{~mm} \text { Schott WG-305, T=92\% } \\
\text { above } 370 \mathrm{~nm}, 0 . \mathrm{D} .>3.0 \text { below } 280 \mathrm{~nm}\end{array}$ \\
\hline OH-PLIF, C4 & Photron SA1 & LaVision IRO (18 mm) & See Fig. 3 & Cerco, $45 \mathrm{~mm}, \mathrm{f} / \mathrm{D}=1.8$ & $\begin{array}{c}5 \mathrm{kHz} / 1024 \times 1 \\
024 \text { pixels }\end{array}$ & 1.8 & $\begin{array}{c}\text { Band-pass: } 320 \mathrm{~nm} / 40 \mathrm{~nm} \text { FWHM }(\mathrm{T}=80 \%)+ \\
315 / 15 \mathrm{~nm} \text { FWHM }(\mathrm{T}=86 \%) \text {, range is up to } \\
500 \mathrm{~nm}\end{array}$ \\
\hline
\end{tabular}



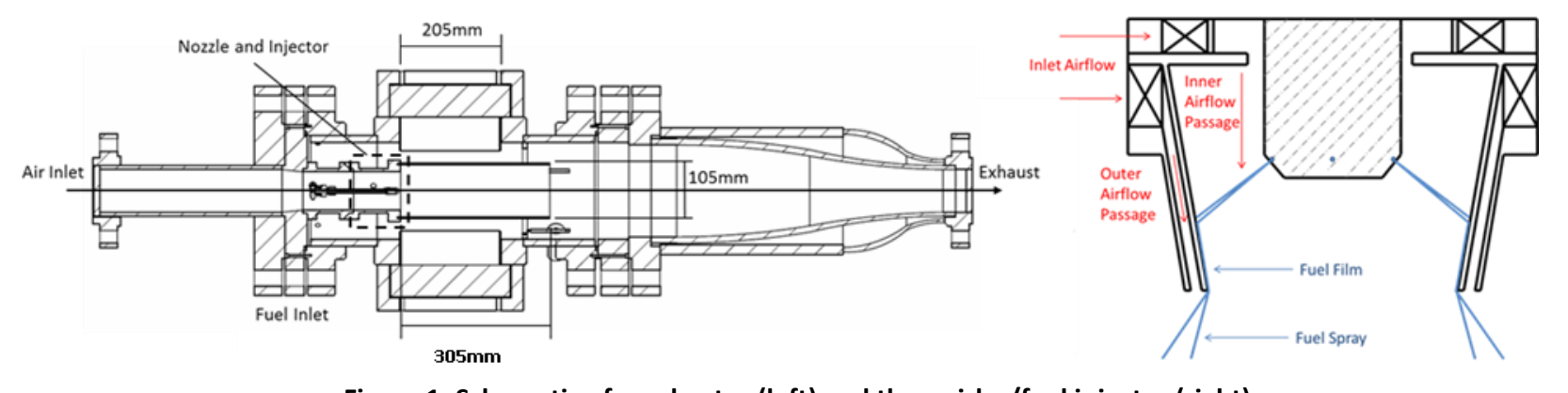

Figure 1: Schematic of combustor (left) and the swirler/fuel injector (right)

-

\section{Figure}

(1) 
Fuel Ignitor

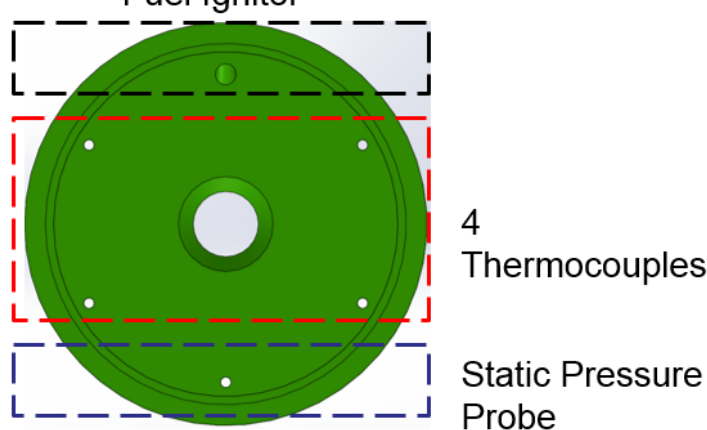

Figure 2: Bulkhead instrumentation placement schematic 


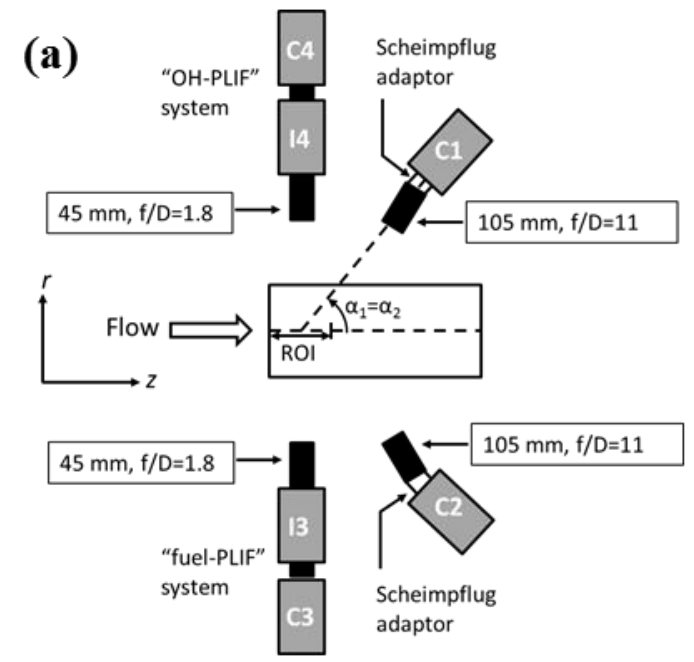

(b)

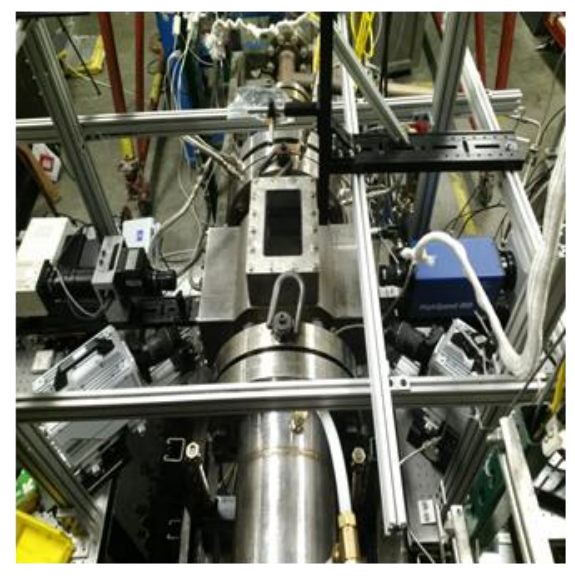

Figure 3: High speed SPIV and 2-Color OH-PLIF camera configuration. C1 and C2 are sPIV cameras, mounted at 45 degrees to laser sheet. C3 is the "fuel-PLIF" camera and C4 is the "OH-PLIF" camera, both coupled to image intensifiers. 


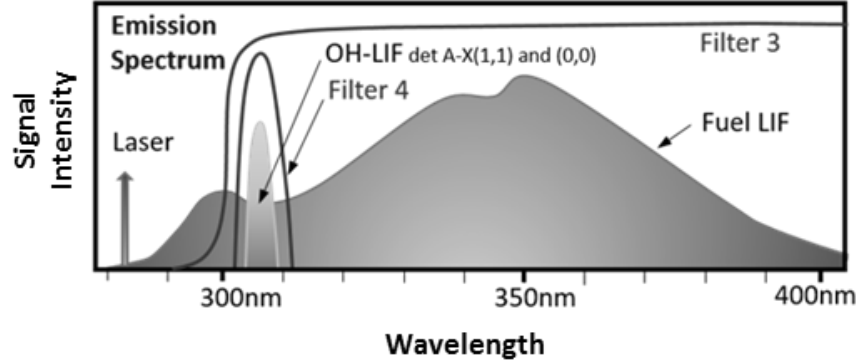

Figure 4: Use of spectral filters to partially separate $\mathrm{OH}$ and fuel-PLIF. 


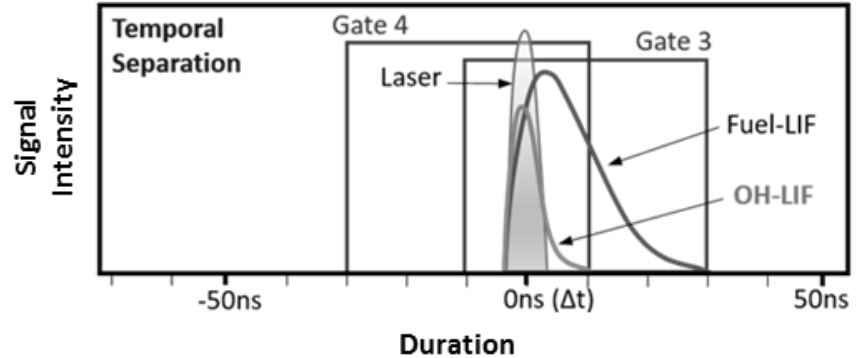

Figure 5: Use of intensifier gate timing to temporally separate fuel and OH-LIF signals. 

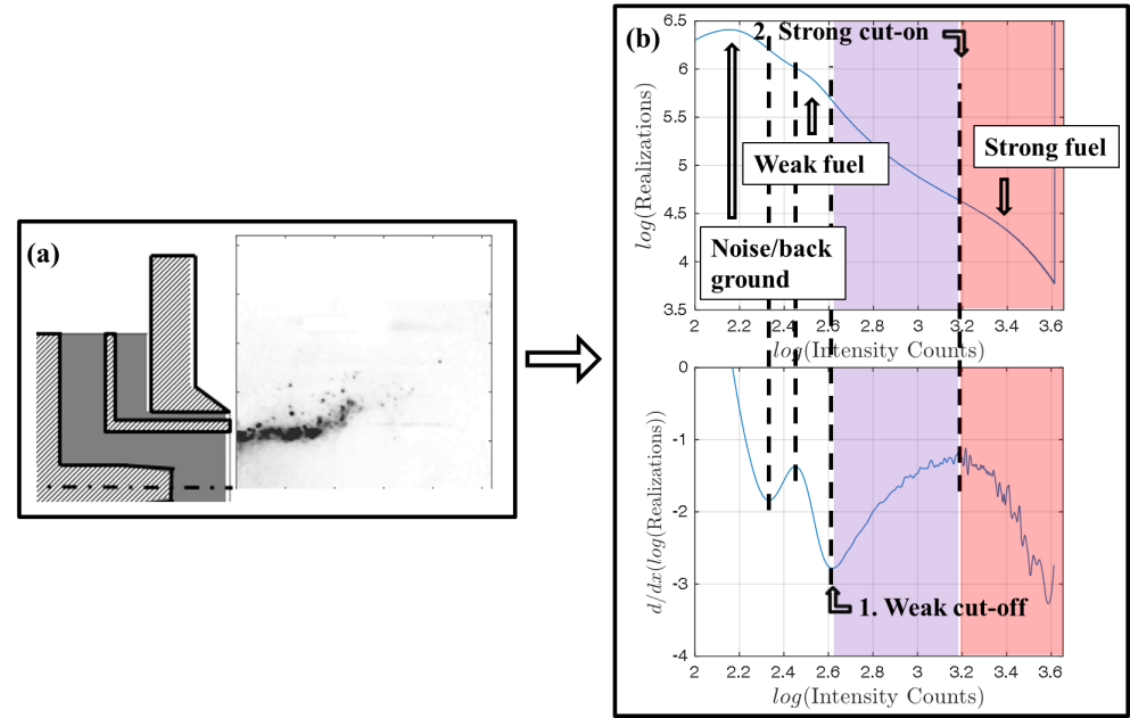

Figure 6: Extracting intensity thresholds from the fuel-PLIF histogram for case 1. Other cases produce similar results. (a): raw fuel-PLIF image. (b): fuel-PLIF intensity histogram and derivative. 


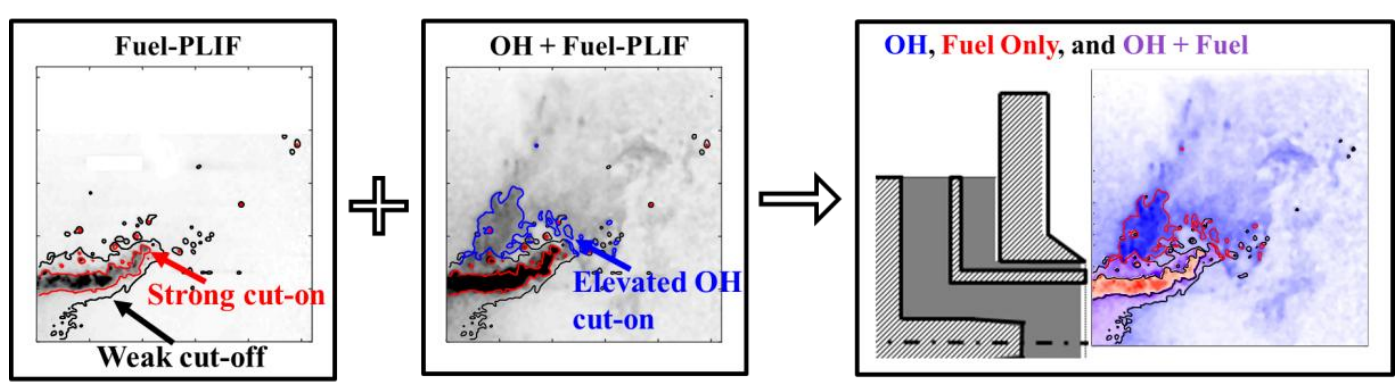

Figure 7: Constructing a false color OH/fuel-PLIF image for case 1. Thresholds lines from Figure 6 are used to split each frame into three regions and create a composite, false color image. The red region contains fuel only signal and is taken from the fuel-PLIF camera; the purple region contains $\mathrm{OH}+$ fuel and is taken from the $\mathrm{OH} /$ fuel-PLIF camera; the blue region shows only $\mathrm{OH}$ signal. 

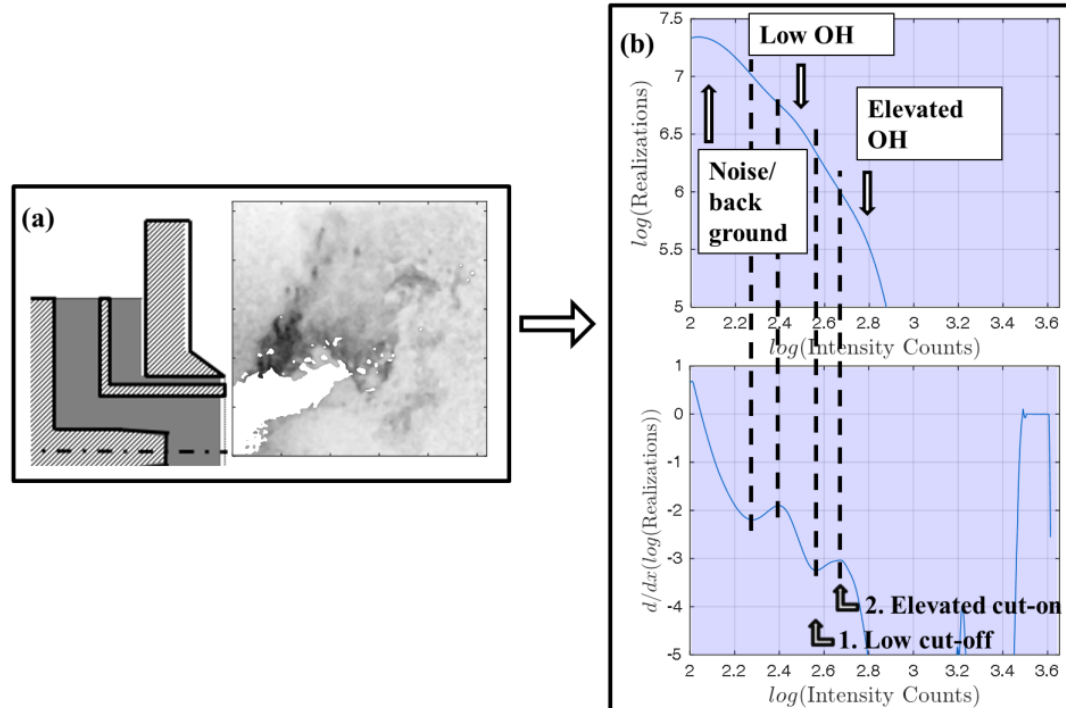

Figure 8: Extracting elevated level cut-on thresholds from the masked-OH-PLIF histogram for case 1. (a): OH-PLIF image, with fuel containing regions masked out using thresholds from Figure 6. (b): Masked OH-PLIF intensity histogram from full data set. 


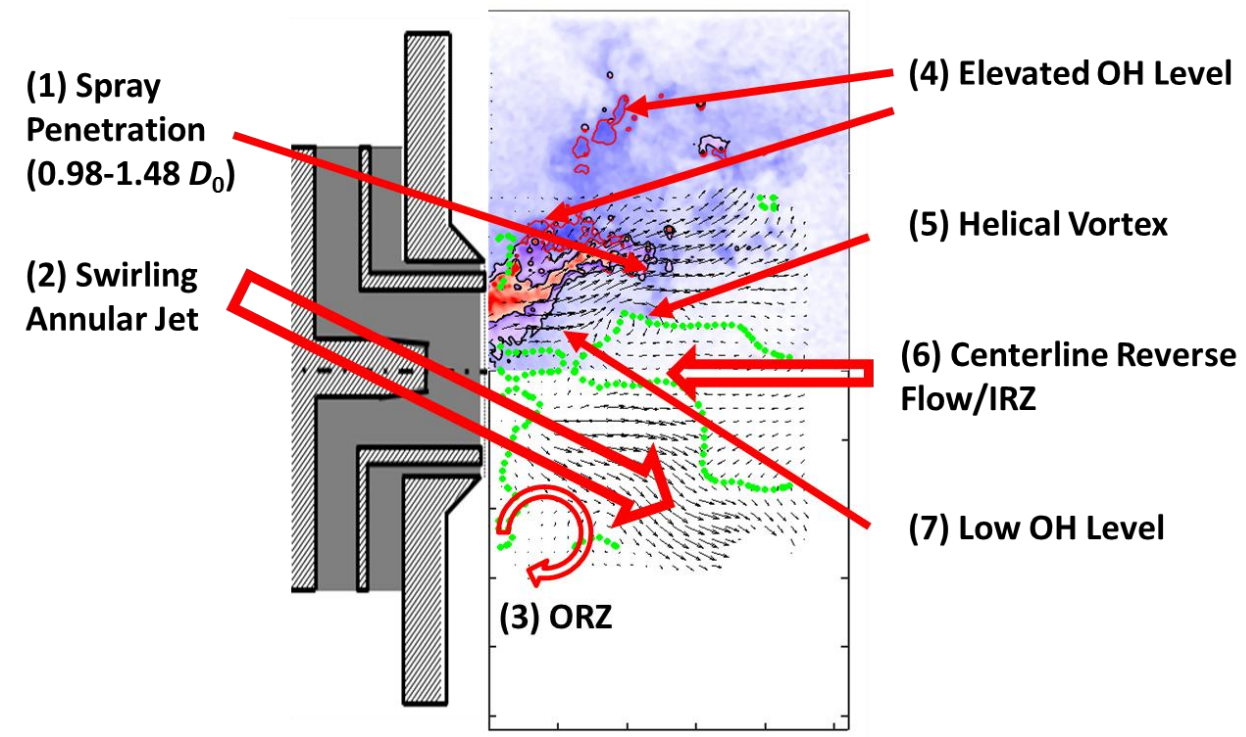

Figure 9: Overlay of instantaneous flow velocity, $\mathrm{OH}$ (blue), fuel (red), and $\mathrm{OH}+$ fuel (purple), showing general flow topological features for Case 1. 

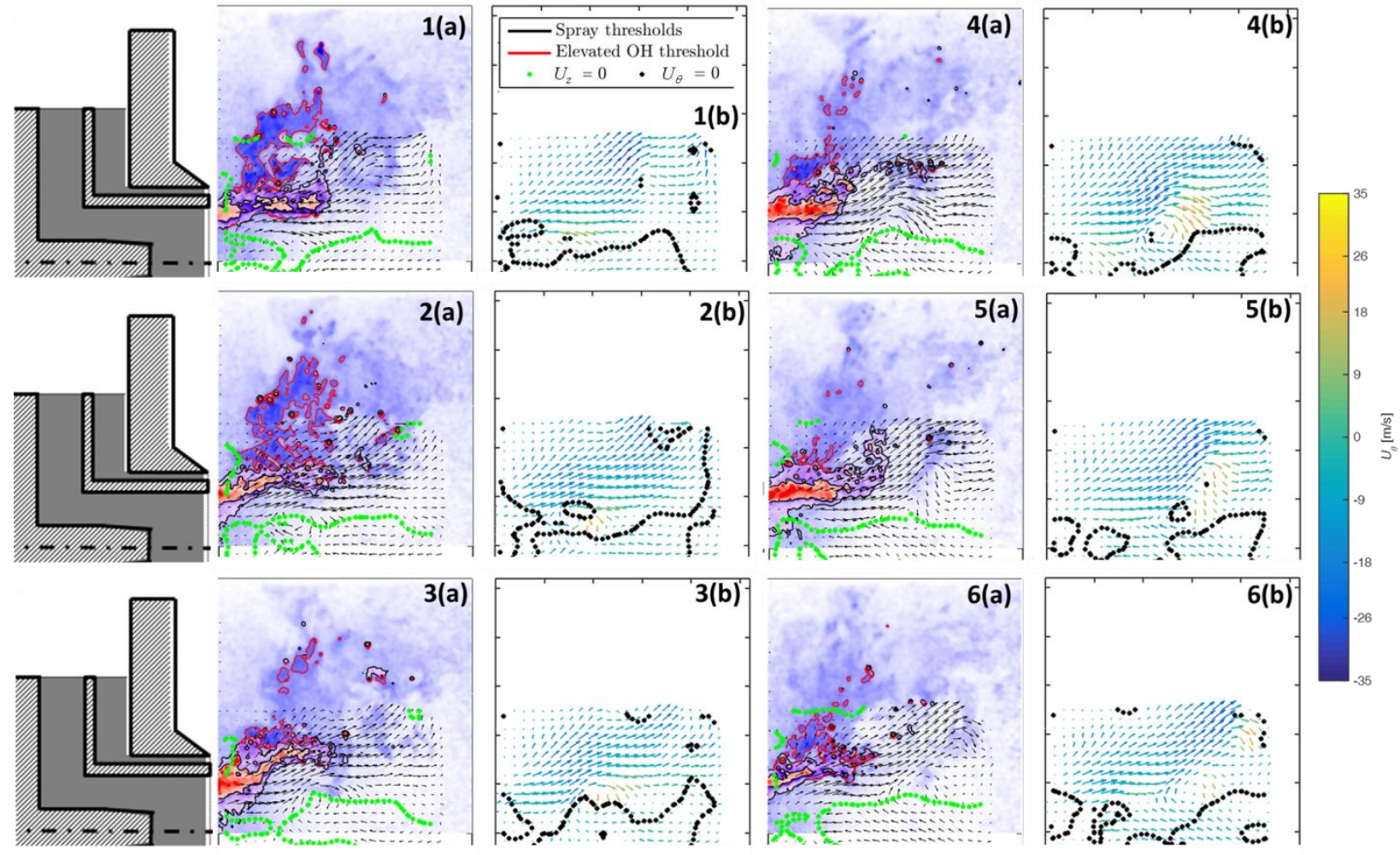

Figure 10: Case 1 instantaneous data. Six frame sequence $(\Delta t=200 \mu \mathrm{s})$ of OH-PLIF (blue), fuel-PLIF (red), mixture of fuel and $\mathrm{OH}$ (purple) and sPIV in (a). Two components of sPIV are shown in (a) with black arrows and all three in (b). $U_{z}=0$ line plotted in (a) (green) and $U_{\theta}=0$ line plotted in (b) (black). 


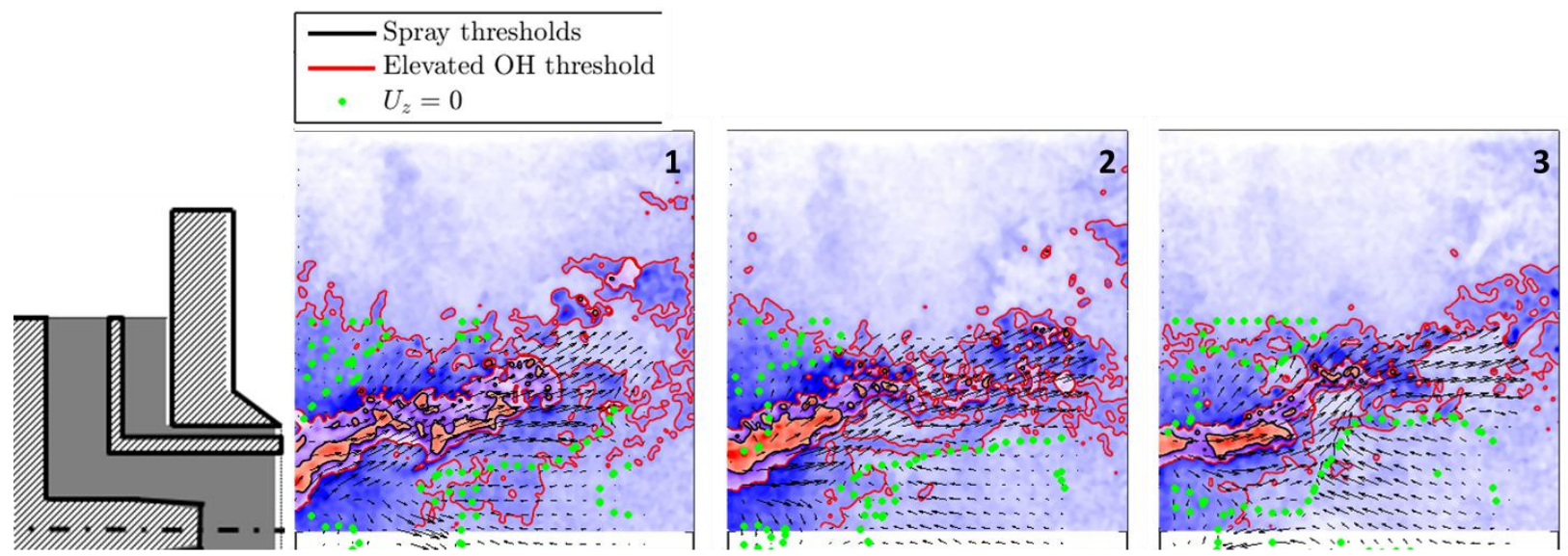

Figure 11: Case 3 instantaneous data. Three frame sequence $(\Delta t=200 \mu \mathrm{s})$ of OH-PLIF (blue), fuel-PLIF (red), mixture of fuel and $\mathrm{OH}$ (purple), and SPIV (black arrows). $U_{\mathrm{z}}=0$ line in green. 


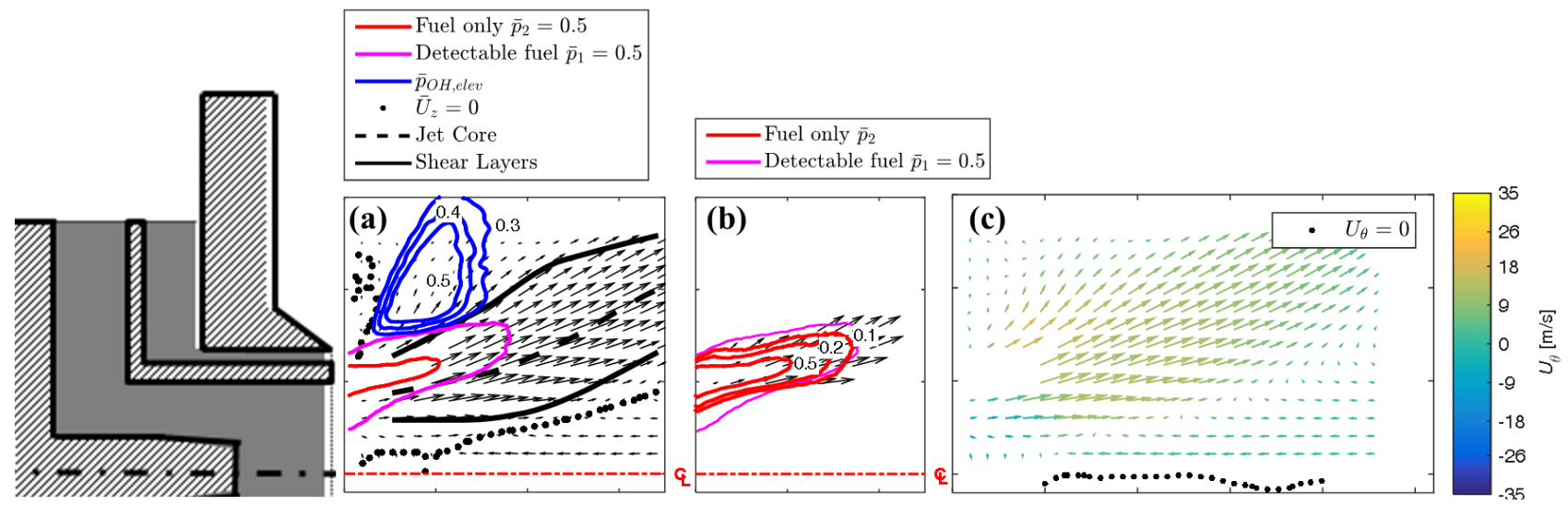

Figure 12: Case 1 time-averaged data. (a): Two components of gas phase sPIV shown along with $U_{z}=0$ line (green). Fuel-PLIF $\bar{p}_{2}=0.5$ line (red) represents $50 \%$ probability of finding fuel spray only. Fuel-PLIF $\bar{p}_{1}=0.5$ line (purple) represents $\mathbf{5 0 \%}$ probability of finding any detectable fuel. The jet core (dashed black) and maximum vorticity (solid black) lines are also shown. $\bar{p}_{O H, \text { elev }}$ field isolines are shown in blue, indicating the flame shape. (b): Fuel-PLIF $\bar{p}_{2}$ field and $\bar{p}_{1}=0.5$ line. (c): All three components of gas phase SPIV along with $U_{\theta}=0$ line (dotted black). The combustor centerline, denoted $C_{L}$, is shown with a dashed red line. 


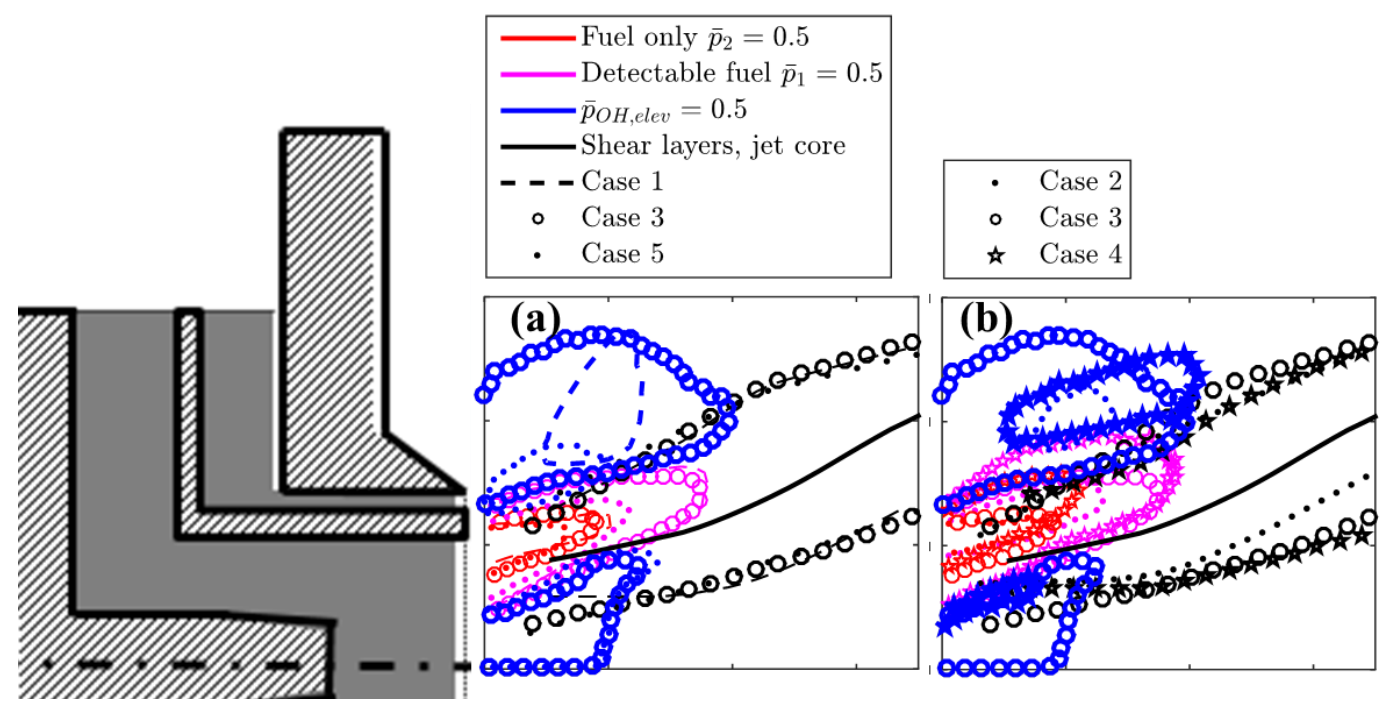

Figure 13: Comparison of time averaged flow features and liquid fuel/OH probability fields (a) across three pressures for cases 1, 3, and 5 with Jet-A, and (b) with fuel C-5 for case 2, and at two preheat temperatures for cases 3 and 4 with Jet-A. The time-averaged inner and outer shear layers (magenta) and jet core (same across cases - black) using gas phase velocity, $\bar{p}_{2}=0.5$ (red), $\bar{p}_{1}=0.5$ (purple) , and $\bar{p}_{\mathrm{OH}, \text { elev }}=0.5$ (blue) lines are shown. Note that for case 2, there is no $\bar{p}_{O H, e l e v}=0.5$ isoline, and the highest probability line, 0.3 , is shown. 

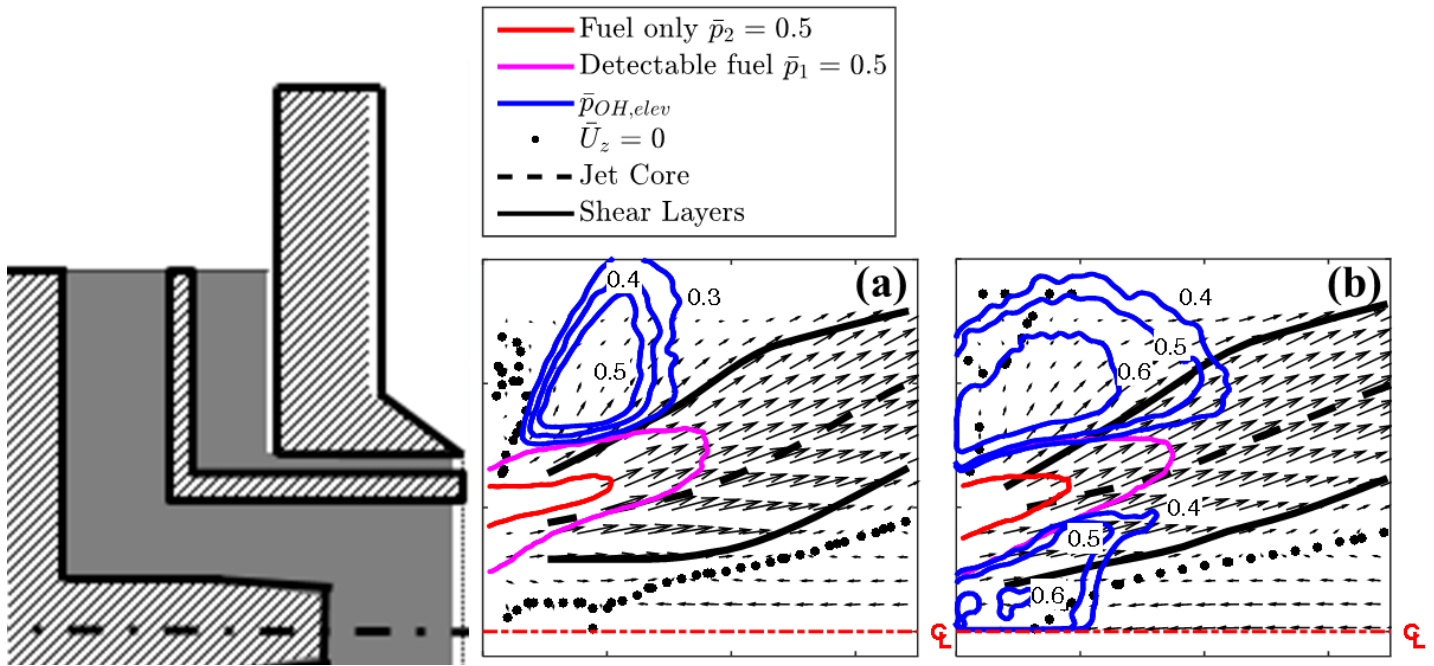

Figure 14: Comparison of two flame shapes encountered for Cases 1(a) and 3(b). Two components of time-averaged gas phase sPIV shown along with $\boldsymbol{U}_{\mathbf{z}}=0$ line (dotted black). Fuel-PLIF $\bar{p}_{2}=0.5$ line (red) represents $50 \%$ probability of finding fuel spray only. Fuel-PLIF $\bar{p}_{1}=0.5$ line (purple) represents $50 \%$ probability of finding any detectable fuel. The jet core (dashed black) and maximum vorticity (solid black) lines are also shown. $\bar{p}_{O H, \text { elev }}$ field isolines (blue) indicate the flame shape. (a) Case 1 has flame configuration I and (b) case 3 has flame configuration II. The combustor centerline is shown with a dashed red line. 
(a)

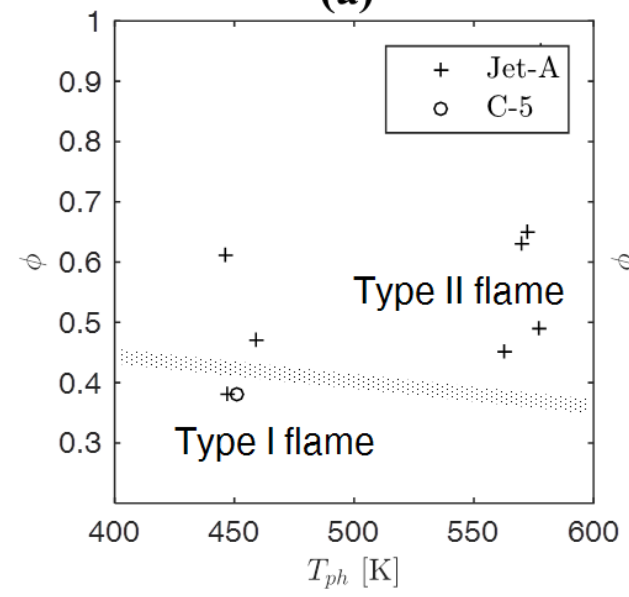

(b)

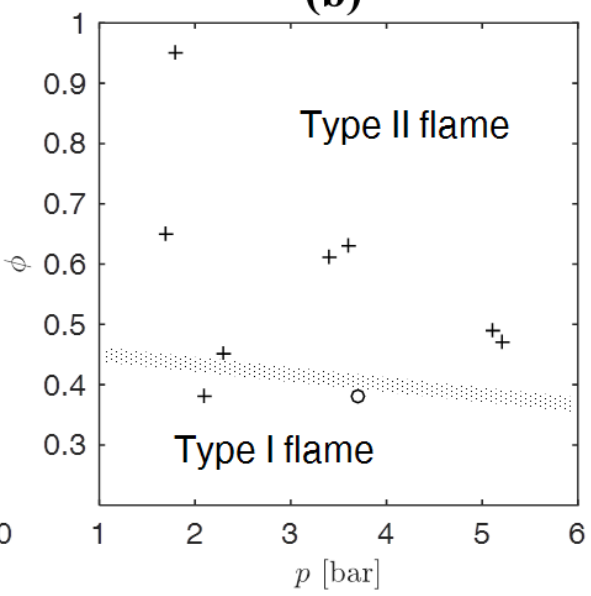

Figure 15: Sensitivity of the flame shape to fuel/air equivalence ratio and (a) preheat temperature or (b) combustor pressure. 


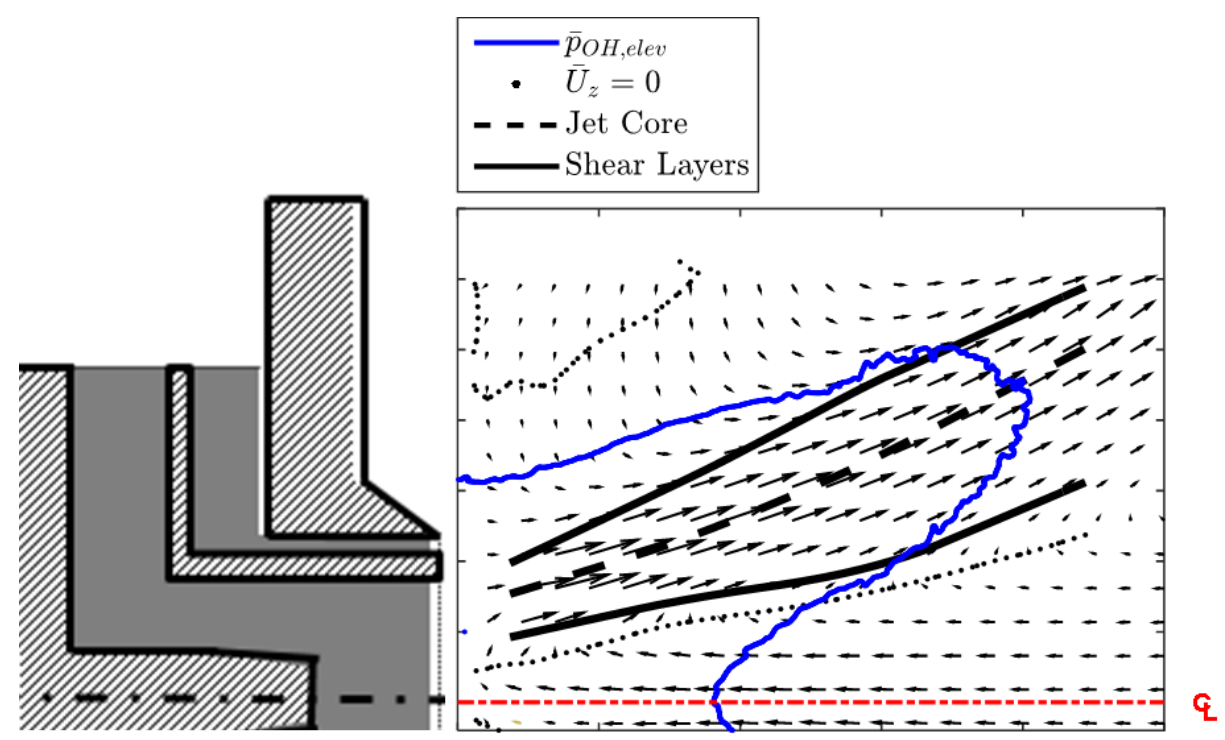

Figure 16: Time-averaged PIV/OH-PLIF data for a premixed gaseous-fueled combustor with high shear swirler from ref. 44. Blue line is $\bar{p}_{\mathrm{OH}, \text { elev }}=0.5$ contour or the average location of the reaction zone. Solid black lines are the shear layers. Dashed black line is jet core. Thin dotted black line is $U_{z}=0$. The combustor centerline is shown with a dashed red line. 


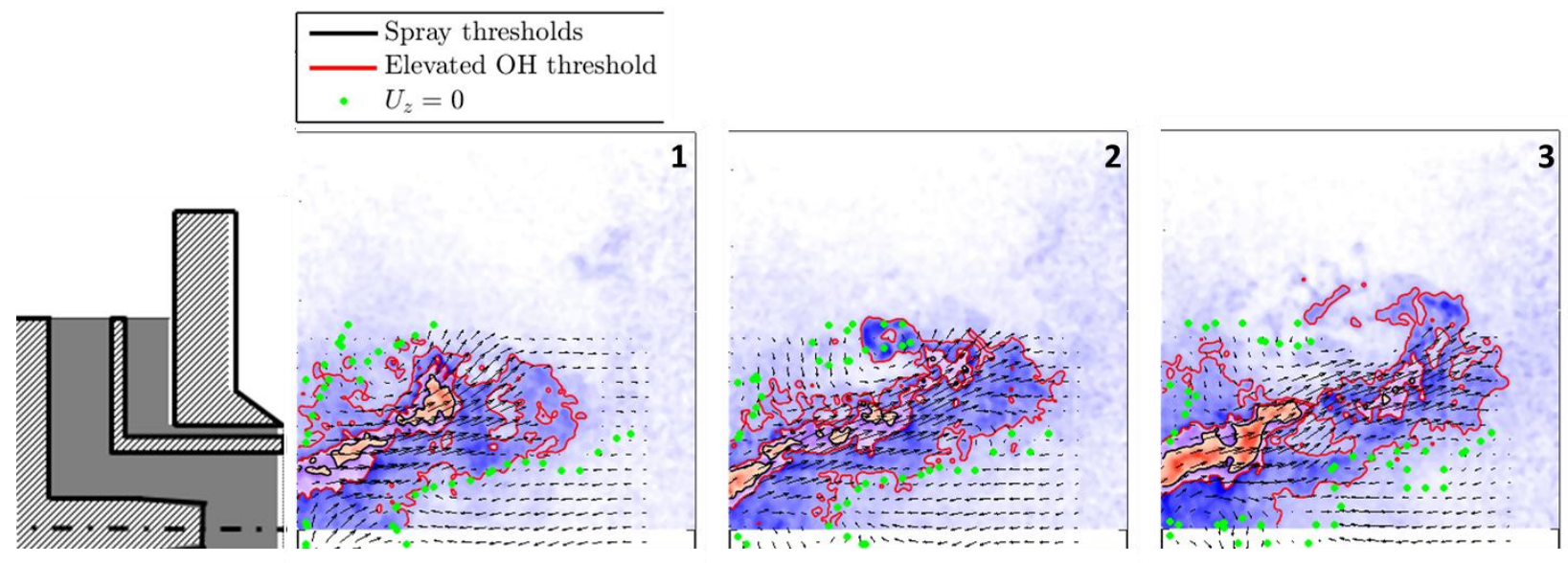

Figure 17: Case 5 instantaneous data. Three frame sequence $(\Delta t=200 \mu \mathrm{s})$ of OH-PLIF (blue), fuel-PLIF (red), mixture of fuel and $\mathrm{OH}$ (purple), and SPIV (black). $U_{\mathrm{z}}=0$ line plotted in green. 

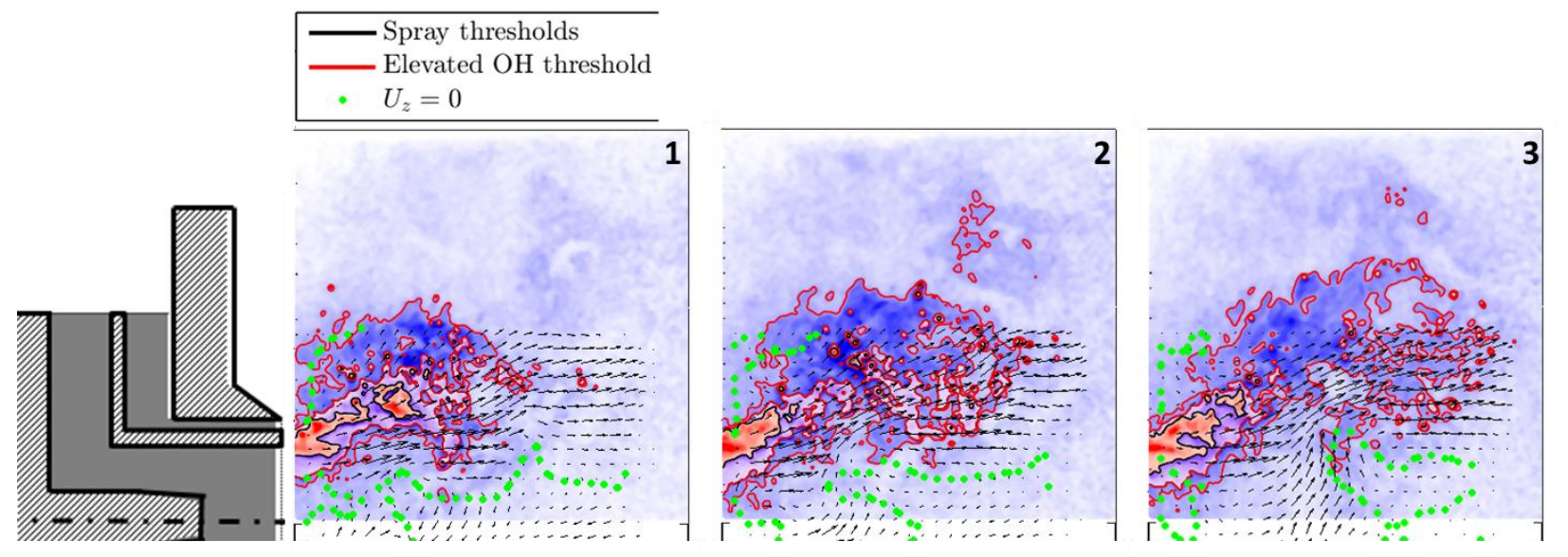

Figure 18: Case 4 instantaneous data. Three frame sequence ( $\Delta \mathrm{t}=\mathbf{2 0 0} \mu \mathrm{s}$ ) of OH-PLIF (blue), fuel-PLIF (red), mixture of fuel and $\mathrm{OH}$ (purple), and sPIV (black). $U_{z}=0$ line plotted in green. 

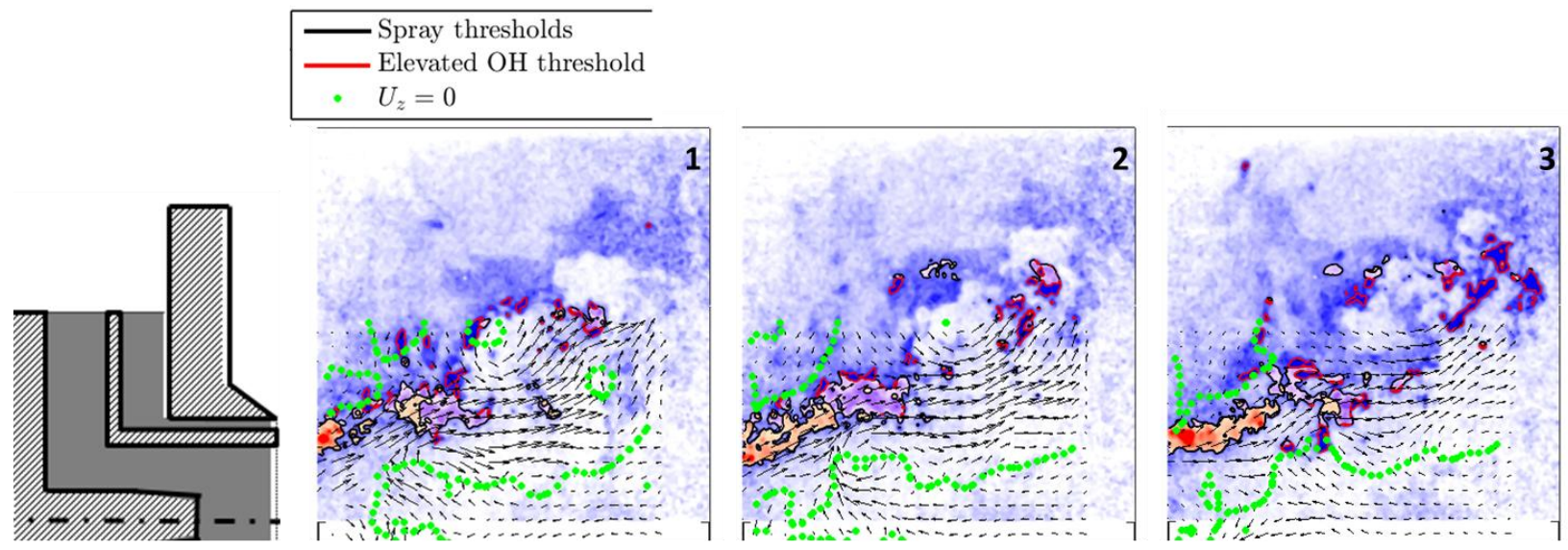

Figure 19: Case 2 instantaneous data. Three frame sequence ( $\Delta \mathrm{t}=200 \mu \mathrm{s})$ of OH-PLIF (blue), fuel-PLIF (red), mixture of fuel and $\mathrm{OH}$ (purple), and sPIV (black). $U_{\mathrm{z}}=0$ line plotted in green. 